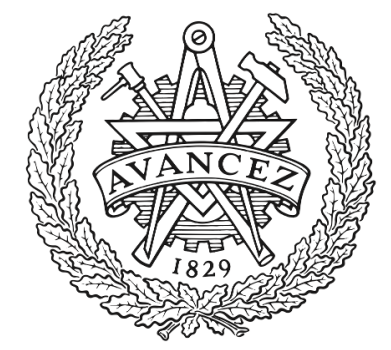

CHALMERS

UNIVERSITY OF TECHNOLOGY

\title{
Fault Detection and Localization for Limp Home Functionality of Three-Level NPC Inverters with Connected Neutral Point for Electric
}

Downloaded from: https://research.chalmers.se, 2023-04-26 14:52 UTC

Citation for the original published paper (version of record):

Kersten, A., Oberdieck, K., Bubert, A. et al (2019). Fault Detection and Localization for Limp Home Functionality of Three-Level NPC Inverters with

Connected Neutral Point for Electric Vehicles. IEEE Transactions on Transportation Electrification, 5(2): 416-432. http://dx.doi.org/10.1109/TTE.2019.2899722

N.B. When citing this work, cite the original published paper.

(O2019 IEEE. Personal use of this material is permitted.

However, permission to reprint/republish this material for advertising or promotional purposes 


\title{
Fault Detection and Localization for Limp Home Functionality of Three-Level NPC Inverters with Connected Neutral Point for Electric Vehicles
}

\author{
Anton Kersten, Student Member, IEEE, Karl Oberdieck, Student Member, IEEE, \\ Andreas Bubert, Student Member, IEEE , Markus Neubert, Student Member, IEEE, Emma Grunditz, \\ Torbjörn Thiringer, Senior Member, IEEE, Rik. W. De Doncker, Fellow, IEEE
}

\begin{abstract}
This paper deals with the detection of single battery or inverter switch faults during operation of a common and an active three-level neutral-point-clamped (NPC) inverter with a connected neutral point. Here, a main focus lies on the detection and localization of open circuit faults of the inverter's switches. Therefore, a fault detection algorithm, using a current estimator, and two fault localization algorithms, a pulse pattern injection principle and an online adaption of the space vector modulation, are investigated and verified through simulations and experiments. Also investigated is how the power-train can be operated under fault condition, so that the vehicle can drive with a limited maximum power using an adapted space vector modulation, referred to as "limp home" mode, to the next service station. It is shown, that an active neutral-point-clamped inverter can cope with any single short or open circuit fault of the inverter's switches without bringing the vehicle to standstill, whereas a generic neutral-point-clamped inverter loses controllability, if an open circuit fault at an inner switch occurs. Furthermore, both inverter types are able to be operated just with half of the DC link voltage in case of a failure in one part of the battery.
\end{abstract}

Keywords-Fault location, Fault tolerance, Multilevel systems, Neutral-point-clamped (NPC), Redundancy, Vehicles.

\section{LIST OF ACRONYMS}

$\begin{array}{ll}\text { ANPC } & \text { Active Neutral Point Clamped } \\ \text { NP } & \text { Neutral Point } \\ \text { NPC } & \text { Neutral Point Clamped } \\ \text { SOC } & \text { State of Charge } \\ \text { SOH } & \text { State of Health } \\ \text { SVM } & \text { Space Vector Modulation } \\ \text { TF } & \text { Transfer Function }\end{array}$

\section{NOMENCLATURE}

$0^{\mathrm{n}} \quad$ Zero state with reverse conduction

$0^{\mathrm{p}} \quad$ Zero state with forward conduction

$f_{1} \quad$ Fundamental frequency

$F_{\text {cq }} \quad$ Q-current controller TF

$f_{\text {sw }} \quad$ Switching frequency

A. Kersten, E. Grunditz and T. Thiringer are with the Department of Electrical Engineering, Division of Electric Power Engineering, Chalmers University of Technology, Gothenburg, 41296 Sweden (e-mail: kersten@chalmers.se). K. Oberdieck, A. Bubert, M. Neubert and R. W. De Doncker are with the Institute for Power Electronics and Electrical Drives (ISEA), RWTH Aachen University, 52066 Aachen, Germany (post@isea.rwth-aachen.de) .

$\begin{array}{ll}G_{\mathrm{cl}} & \text { Closed loop TF } \\ G_{\mathrm{cq}}^{\prime} & \text { Motor q-current TF with active damping } \\ G_{\mathrm{cl}-\mathrm{cq}} & \text { Closed loop q-current TF } \\ i_{\mathrm{NP}} & \text { Neutral point current } \\ i_{\mathrm{sd}} & \text { Stator current in direct-axis } \\ i_{\mathrm{sdq}} & \text { Stator current in dq-quantities } \\ i_{\mathrm{sq}} & \text { Stator current in quadrature-axis } \\ i_{x} & \text { Phase current with }\{a, b, c\} \in x \\ I_{x, \text { avg }} & \text { Average current with }\{a, b, c\} \in x \\ i_{x, \mathrm{n}} & \text { Negative phase current with }\{a, b, c\} \in x \\ i_{x, \mathrm{p}} & \text { Positive phase current with }\{a, b, c\} \in x \\ K_{\mathrm{icd}} & \text { Integrative d-current control gain } \\ K_{\mathrm{icq}} & \text { Integrative q-current control gain } \\ K_{\mathrm{pcd}} & \text { Proportional d-current control gain } \\ K_{\mathrm{pcq}} & \text { Proportional q-current control gain } \\ Q_{x, \mathrm{p}} & \text { Positive phase charge with }\{a, b, c\} \in x \\ Q_{x, \mathrm{n}} & \text { Negative phase charge with }\{a, b, c\} \in x \\ R_{\mathrm{ad}} & \text { Active damping in direct-axis } \\ R_{\mathrm{aq}} & \text { Active damping in quadrature-axis } \\ R_{\mathrm{s}} & \text { Stator resistance } \\ S_{x} & \text { Switching state of phase leg } x \\ T_{\mathrm{sw}} & \text { with }\{a, b, c\} \in x \\ V_{x-\mathrm{NP}} & \text { Switching/sample time } \\ \alpha & \text { Phase voltage } x \text { with }\{a, b, c\} \in x \\ \alpha_{c} & \text { Control bandwidth } \\ \Delta_{\mathrm{Fault}, \mathrm{thr}} & \text { Furrent control bandwidth } \\ \Delta_{\mathrm{Trans}, \mathrm{thr}} & \text { Transient threshold } \\ \theta_{\mathrm{r}} & \text { Rotor position } \\ \omega_{\mathrm{r}} & \text { Rotor speed } \\ & \end{array}$

\section{INTRODUCTION}

In the field of vehicle traction applications, two-level inverter topologies are widely spread and vastly used, due to their maturity. However, these do not offer any redundancy under fault condition, instead the vehicle's power-train loses controllability and might have to stall. To mitigate this, redundant two-level inverter topologies, where additional inverter legs or switches are paralleled and intricate short circuit protection circuitry is applied, have been proposed [1]. Multilevel inverter topologies, on the other hand, can offer redundancy with additional benefits such as common mode voltage reduction, power density enhancement or stress reduction of the switches [2]. Therefore, 


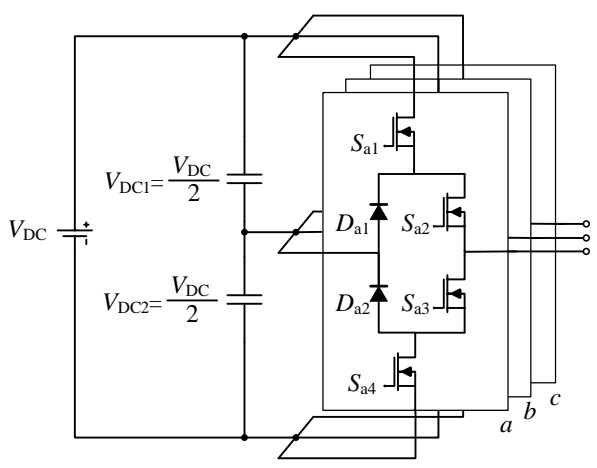

(a) NPC inverter

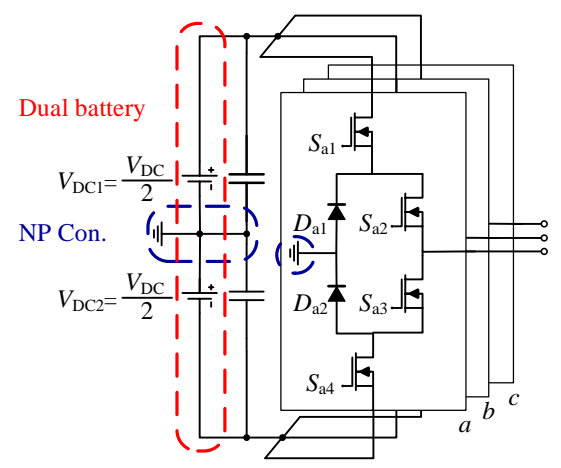

(b) NPC inverter with NP connection



(c) ANPC inverter with NP connection

Fig. 1: NPC inverter topologies.

the three-level neutral-point-clamped (NPC) inverter, which was introduced by Nabae in 1981 [3], is under consideration for vehicle traction applications [4], [5]. Commonly, the threelevel NPC inverter, as shown in Fig. 1 (a), is supplied by a single DC source, hence no redundancy is provided. Therefore, a neutral point connection in the double battery pack can introduce a limp home functionality [6], which makes it possible to operate the vehicle with limited maximum power by utilizing an adapted space vector modulation, thus the vehicle could drive to the next service station without requiring a towing service. However, an accurate and fast fault detection is required to diagnose a limp home functionality. Within the frame of this investigation, the detection, localization and mitigation of single faults of the dual battery and inverter's switches of an NPC inverter with a connected neutral point are investigated. The possibility to operate the power train under fault condition is demonstrated. Here, a common NPC and an active NPC (ANPC) inverter, utilizing MOSFETs in the clamping paths, are considered, as can be seen in Figs. 1(b) and 1 (c), respectively.

\section{A. Literature Review}

The main focus of this analysis is on the detection and localization of open circuit faults of the inverter's switches. Literature contains several fault detection and localization methods for generic NPC converters, mainly used in grid connected applications, operating as rectifier or inverter [7][17]. Here, two main approaches, without requiring additional circuitry, can be distinguished, which are described in [7][14]. These are either based on sensing the three-phase output currents [7]-[11] or the DC link voltage ripple distortion [12][14]. During fault condition, the average output current in the $\alpha \beta$-plane surpasses a nonzero threshold [7], [8], which can be used in combination with the characteristic shape of the currents $[9]-[11]$ to detect and localize the open circuit fault. A quite similar approach is the sensing of the DC link ripple trajectories in the $\alpha \beta$-plane [12]-[14]. However, the presented approaches require up to two fundamental periods to detect the error, the differentiation between a fault at an inner switch and the clamping diode is not accurate and the DC link sensing cannot be implemented, if a connected neutral point topology is chosen. In [15] a different approach for a single phase NPC inverter for a railway application was analyzed. In this case the switching states are used to determine an estimation of the instantaneous load current, which is compared with a high sampled load current. The fault detection is triggered, if the difference of the estimation and measurement exceeds a certain threshold. A similar method for a three-phase NPC inverter has been implemented in [16] and [17], requiring additional sensors, either for the neutral point current or the PWM output voltage. However, the measurement of a switched current or voltage requires a high bandwidth, the detection algorithm must be executed multiple times faster than the switching frequency and an additional sensor comes with an extra cost and bears a risk of failure. To sum up, missing in literature is a fault-tolerance analysis and a software-based single open circuit fault detection and localization algorithm for a common and active NPC traction inverter with a connected neutral point, which allows for a continued operation directly after a fault has occurred.

\section{B. Key Contributions}

The contribution of this article is to present how all types of inverter faults, as well as non-destructive battery faults, can be handled and how the vehicle can be brought over to a reduced performance mode. A new, simple open circuit fault detection algorithm using a current estimator and the algorithm's performance are analyzed. Furthermore, two, new fault localization algorithms, using a pulse pattern injection principle and an online adaption of the space vector modulation, are investigated and verified through simulations and experiments.

\section{Paper Organization}

The remainder of this paper is divided into six sections. In Section II, the operation of the three-level NPC inverter with connected neutral point is described. Section III shows, with the help of an example drivetrain, the potential to overcome single battery and inverter faults. Based on this, Section IV and $\mathrm{V}$ introduce a standstill and online open circuit fault diagnostic algorithm, respectively. The algorithms are experimentally verified in Section VI, followed by conclusions in Section VII. 


\section{NPC InVERTER With Neutral Point ConNeCtion}

A common approach to operate and produce a certain output voltage with a three-level NPC multilevel inverter is space vector modulation (SVM) [18], [19]. Each phase leg is operated by the three switching states $\{1,0,-1\} \in S_{x}$, which results in the output voltage

$$
V_{x-\mathrm{NP}}=\frac{V_{\mathrm{DC}}}{2} S_{x}
$$

The desired output voltage is created by a mean of switching combinations within one sampling interval. The space vector diagram of a three-level NPC inverter in the $\alpha \beta$-plane is shown in Fig. 2 The maximum RMS line voltage, that can

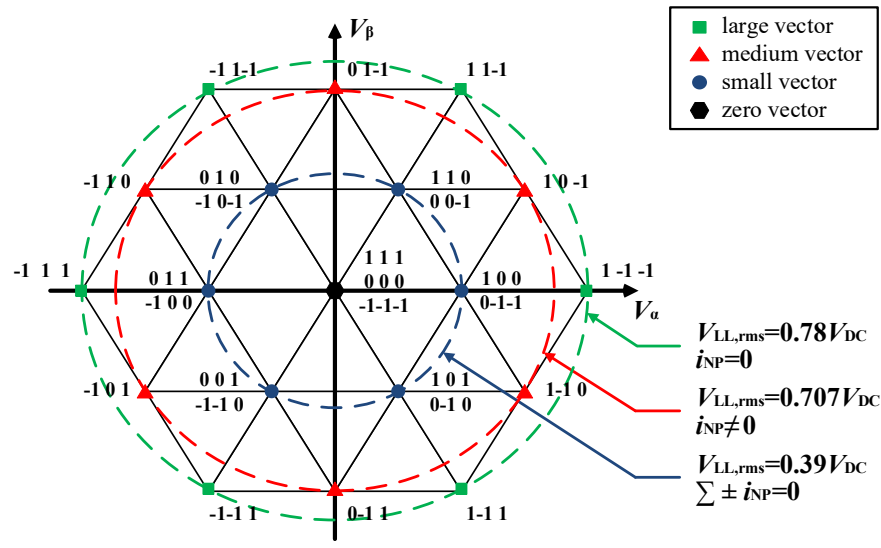

(a)

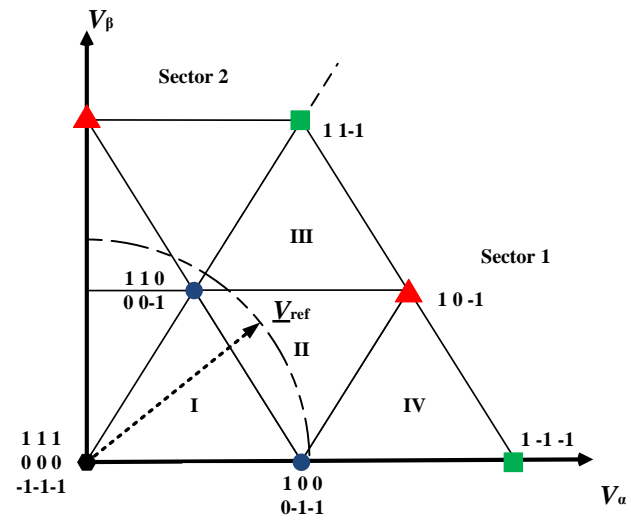

(b)

Fig. 2: Space vector diagram of a three-level inverter (a) [6] and voltage reference in region II of sector 1 (b).

be produced without introducing low order harmonics is

$$
V_{\mathrm{LL}, \mathrm{rms}}=\frac{V_{\mathrm{DC} 1}+V_{\mathrm{DC} 2}}{\sqrt{2}}=0.707 V_{\mathrm{DC}}
$$

Consequently, if one voltage source ceases to supply, the maximum output voltage is halved. When operating with SVM a characteristic current spectrum can be noticed on the DC side of the NPC inverter. According to [18]-[20], a third harmonic current component, referred to as neutral point current, is conducted on the positive and negative DC link rail of the NPC inverter, closing through the capacitors and midpoint connection of the inverter, which can be depicted as seen in Fig. 3.a). This causes the capacitors' voltages to oscillate with

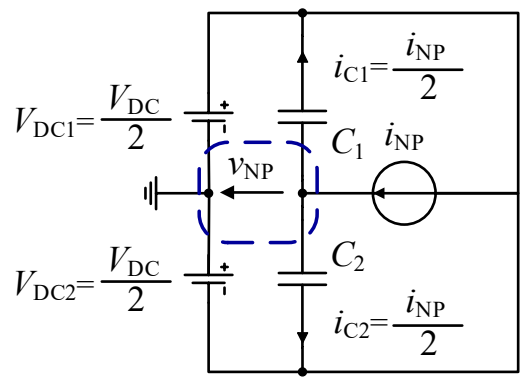

(a)

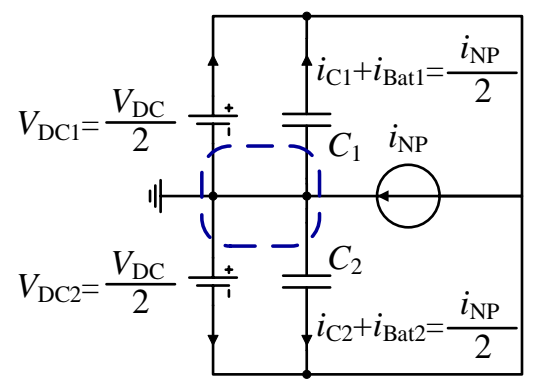

(b)

Fig. 3: Third harmonic current propagation paths with capacitor voltage oscillation (a) and connected NP (b).

a frequency three times that of the output voltage. Especially, at low frequencies and stand still, the reactance of the capacitors is high, which in turn results in a high voltage oscillation. This oscillation appears as an unbalance of the DC capacitors, whereby the semiconductor switches can suffer a higher voltage than under nominal conditions. For this reason, several voltage oscillation mitigation techniques can be found in the literature [6], [21]-[27]. Within the inner hexagon the neutral point current, and thereby the voltage oscillation, can easily be cancelled out by the equivalent usage of redundant small vectors [21]. However, at higher modulation indices, the usage of small vectors is limited, whereas the used medium vectors inevitably introduce a neutral point current. On the contrary, a neutral point connection to a dual battery pack removes the capacitors' voltage oscillations by providing another low impedance path for the third harmonic current through the batteries, as can be seen in Fig. 3(b). According to [28], [29], a "cycling" caused by a low frequency current, except for the increased RMS current, does not lead to an additional aging of the battery. For this reason it is just important to mitigate the third harmonic current in terms of battery, motor and inverter losses by adapted space vector modulation techniques, as for example described in [6], [21], [22], [27]. Furthermore, another important advantage of the neutral point connection is the possibility to operate the power train just with a single battery or under a single switch fault, referred to as "limp home" mode. 


\section{FAULT DETECTION AND OPERATION UNDER FAULT CONDITION}

Within this section, single battery or single inverter faults and the controllability of the drive-train are analyzed. Motor faults are not considered, because the introduced topology with its neutral point connection does not alter the interaction with the motor. Furthermore, the main focus of this analysis is on the detection of open circuit switch faults. For the analysis, a small passenger vehicle driven by an $84 \mathrm{~kW}$ rated interior permanent magnet machine is used to exemplify the operation under different fault conditions. The parameters of the motor and the vehicle can be seen in TABLE I. These are similar to [30], [31]. For the simulated drive train, the DC link, $V_{\mathrm{DC}}$, is $400 \mathrm{~V}$ and the switching or sample frequency of the SVM is set to $f_{\mathrm{sw}}=10 \mathrm{kHz}$, which is typical for vehicle applications. To control the drive train, a cascaded control with an outer speed and an inner current control loop, as can be seen in Fig. 4(a), is used. The field oriented control requires

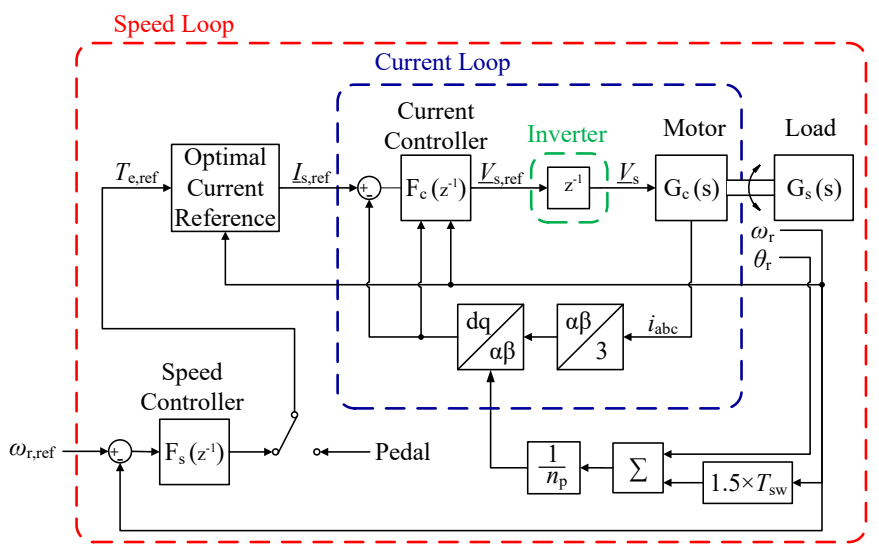

(a)

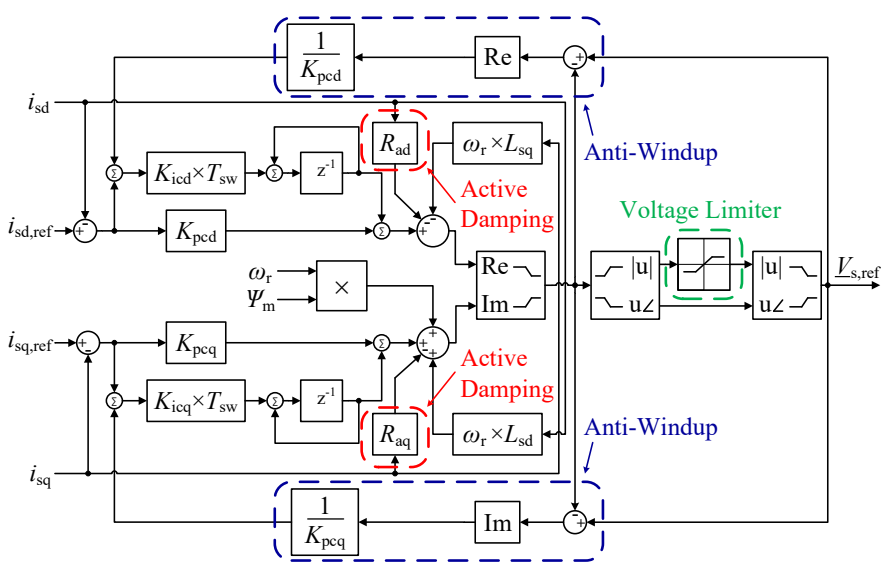

(b)

Fig. 4: Cascaded control of the drivetrain (a) and current control in dq-frame (b).

the motor's rotor position, which is compensated, due to the discrete sample delay of the inverter [32]. The dq-currents are separately controlled, all nonlinearities are cancelled out by feedforward terms, a voltage limiter and antiwindup are implemented, as shown in Fig. 4[b) [32]. All controllers were designed in continuous time using loop shaping, which aims to achieve a first order closed loop TF with the bandwidth $\alpha$ as

$$
G_{\mathrm{cl}}(s)=\frac{\alpha}{s+\alpha}=\frac{F(s) G(s)}{1+F(s) G(s)} .
$$

For example, the motor's TF in quadrature-frame, including active damping, can be rewritten as

$$
G_{\mathrm{cq}}^{\prime}(s)=\frac{1}{L_{\mathrm{sq}} s+R_{\mathrm{s}}+R_{\mathrm{aq}}}
$$

and the quadrature-current controller $F_{\text {cq }}$ (PI controller) should be parametrized to attain the closed loop TF as

$$
G_{\mathrm{cl}, \mathrm{cq}}(s)=\frac{i_{\mathrm{sq}}}{i_{\mathrm{sq}, \mathrm{ref}}}=\frac{\alpha_{\mathrm{c}}}{s+\alpha_{\mathrm{c}}}=\frac{F_{\mathrm{cq}}(s) G_{\mathrm{cq}}^{\prime}(s)}{1+F_{\mathrm{cq}}(s) G_{\mathrm{cq}}^{\prime}(s)} .
$$

Therefore, the controller's parameters are determined as

$$
F_{\mathrm{cq}}(s)=\alpha_{\mathrm{c}} L_{\mathrm{sq}}+\frac{\alpha_{\mathrm{c}}\left(R_{\mathrm{s}}+R_{\mathrm{aq}}\right)}{s}=K_{\mathrm{pcq}}+\frac{K_{\mathrm{icq}}}{s} .
$$

To comply with the desired control bandwidth, the active damping is accordingly parametrized as

$$
G_{\mathrm{cq}}^{\prime}(s)=g \frac{\alpha_{\mathrm{c}}}{s+\alpha_{\mathrm{c}}}=\frac{1}{L_{\mathrm{sq}} s+R_{\mathrm{s}}+R_{\mathrm{aq}}},
$$

which results in

$$
R_{\mathrm{aq}}=\alpha_{\mathrm{c}} L_{\mathrm{sq}}-R_{\mathrm{s}}
$$

TABLE I: Drive-train parameters

(a) Vehicle

\begin{tabular}{ccc}
\hline & Value & Unit \\
\hline Vehicle mass $m_{\mathrm{veh}}$ & 1500 & $\mathrm{~kg}$ \\
Occupant weight $m_{\mathrm{occ}}$ & 75 & $\mathrm{~kg}$ \\
Frontal area $A$ & 2.2 & $\mathrm{~m}^{2}$ \\
Drag cofficient $C_{\mathrm{d}}$ & 0.28 & $\mathrm{~m}^{2}$ \\
Rolling resistance $C_{\mathrm{r}}$ & 0.009 & \\
Wheel radius $r_{\text {wheel }}$ & 0.316 & $\mathrm{~m}$ \\
Gear box ratio $G_{\mathrm{r}}$ & 10.2 & \\
Gearbox efficiency $\eta_{\mathrm{G}}$ & 95 & $\%$ \\
Top speed $v_{\max }$ & 140 & $\mathrm{~km} / \mathrm{h}$ \\
\hline
\end{tabular}

(b) Motor-PMSM

\begin{tabular}{ccc}
\hline & Value & Unit \\
\hline Stator resistance $R_{\mathrm{s}}$ & 20 & $\mathrm{~m} \Omega$ \\
D-axis inductance $L_{\mathrm{sd}}$ & 250 & $\mu \mathrm{H}$ \\
Q-axis inductance $L_{\mathrm{sq}}$ & 700 & $\mu \mathrm{H}$ \\
Flux constant $\psi_{\mathrm{m}}$ & 75 & $\mathrm{mWb}$ \\
Pole pairs $n_{\mathrm{p}}$ & 4 & \\
Max torque $T_{\max }$ & 200 & $\mathrm{~N} \mathrm{~m}$ \\
phase current $I_{\mathrm{RMS}}$ & 190 & $\mathrm{~A}$ \\
phase voltage $\hat{V}_{\mathrm{pk}}$ & 230 & $\mathrm{~V}$ \\
Max speed $n$ & 12000 & $\mathrm{rpm}$ \\
\hline
\end{tabular}




\section{A. Battery Faults}

Battery faults or charge imbalances are supposed to result either in single battery operation [6] or asymmetric voltage operation [33]. The root of the fault can be an external single battery short circuit [34], different SOC/SOH of the batteries [35]-[37], etc. External short circuit faults in either of the battery packs, should be detected by the BMS of the battery, triggering the corresponding battery relay to trip. Consequently, the power train can be operated with half of the rated power, since the possible output voltage is limited to the inner hexagon (small vectors) of the space vector scheme. The torque boundaries of the motor, supplied by a complete and half DC link for the small passenger vehicle are shown in Fig. 5 as Motor Limits I and Motor Limits II, respectively. Different drive cycle operating points, according to [5], are also depicted. It can be seen, that the drive train can cope

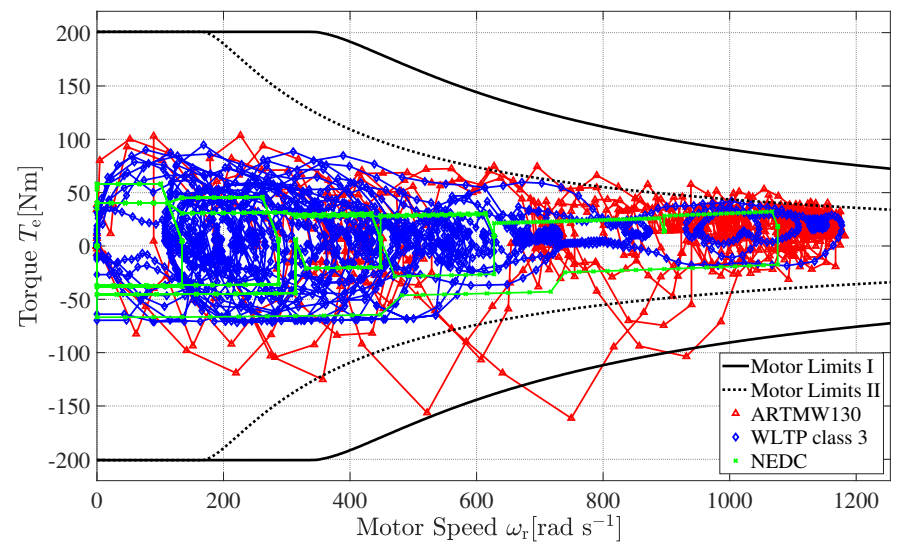

Fig. 5: Motor limits I and II with full DC link and half DC link voltage, respectively.

easily with the operating points at low speeds, whereas the high speed region is slightly compromised. The required time to reach $100 \mathrm{~km} / \mathrm{h}$ from standstill increased from initial $10.1 \mathrm{~s}$ to $20.1 \mathrm{~s}$ for limit I and II, respectively. In case of unequal battery voltages, the SVM scheme can be adapted, without a significant reduction of the output power [33], [38], [39]. Unequal battery voltages can be caused by different $\mathrm{SOHs}$ and unsymmetrical load conditions. Fig. 6 depicts the distortion of the space vector diagram. It can be seen, that a rotating field can still be created. [32].

\section{B. Inverter Faults}

In general, inverter short circuit faults can be detected, and the inverter protected, by additional gate driver circuitry, for example as described in [40]-[42]. Since the switches are operated in pairs, a shoot-through is caused, when three switches in series are unintentionally conducting. If the NPC inverter's short circuit protection is triggered at one or multiple switches, the localization of the fault (for example in a diode or a switch) can be determined by the switching states before and during the event of the short circuit [41]. If the location of the short circuited switch is known, the space vector modulation

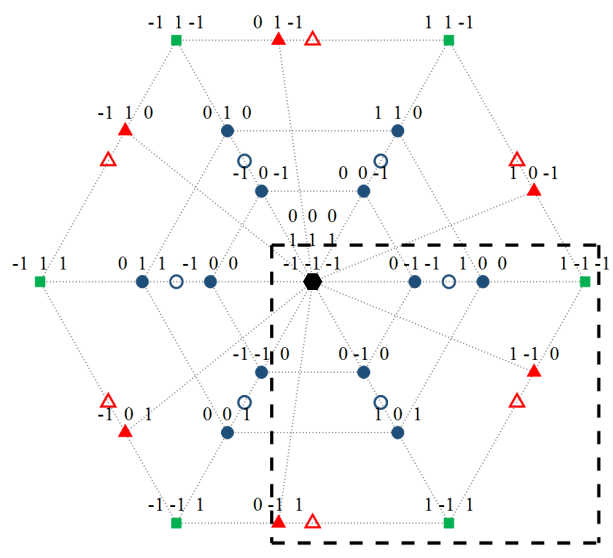

(a)

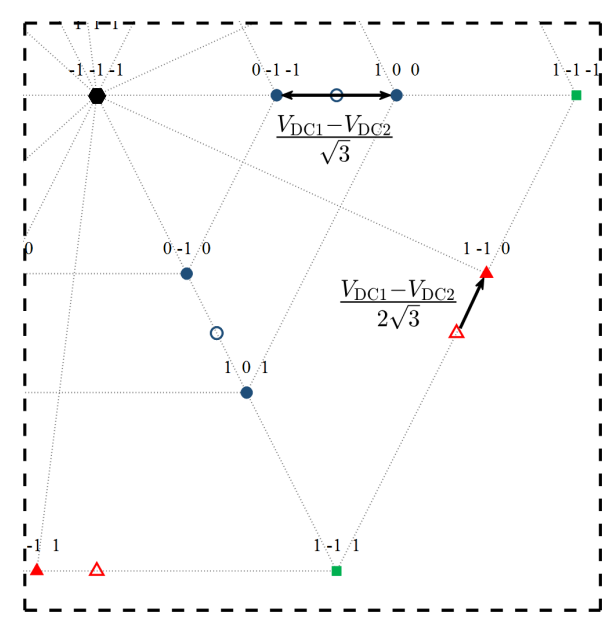

(b)

Fig. 6: Asymmetric space vector modulation scheme (a) and relation of vector distortion (b).

can be adapted to single source operation (small vectors) or the faulty leg can be run in two-level operation (large vectors), as can be seen in Fig. 7 Because of the topology symmetry, it is enough to consider just one half leg. It is seen that a single short circuit fault does not lead to a stall of the drive train, which is a great advantage compared to a classical twolevel inverter. In contrast to short circuit faults, open circuit faults of the inverter are difficult to detect and to localize. Further, there is a need to distinguish between an open circuit fault due to a switch breakdown or to a control circuit fault [43]. Here, it has to be mentioned that a pure open circuit fault (package diode and switch are in open circuit condition) due to breakdown at the switch, would cause an over-voltage, which most likely destroys the circuit. Nevertheless, the most common open circuit faults originate from the drive circuit side. For these reasons, open circuit faults of the clamping diodes/MOSFETs, semiconductor switches and control circuits can be detected. If the fault type and location is known, the space vector diagram changes its valid states according to Fig. 8. In case of an open circuit fault at an inner switch, the NPC inverter loses controllability of the current in four 


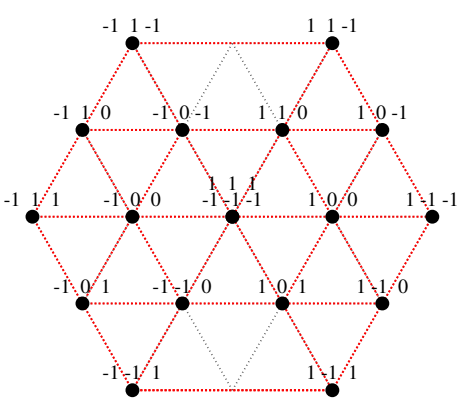

(a) NPC - $S_{\mathrm{a} 1}-$ short

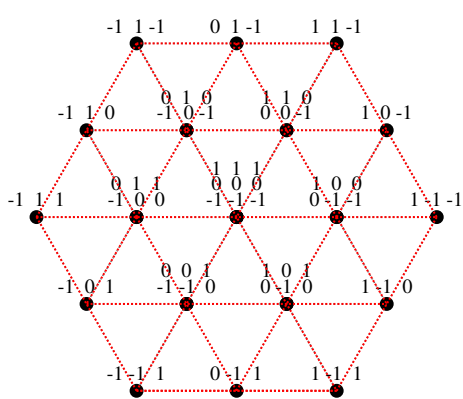

(d) ANPC - $S_{\mathrm{a} 1}-$ short



(b) NPC - $S_{\mathrm{a} 2}-$ short

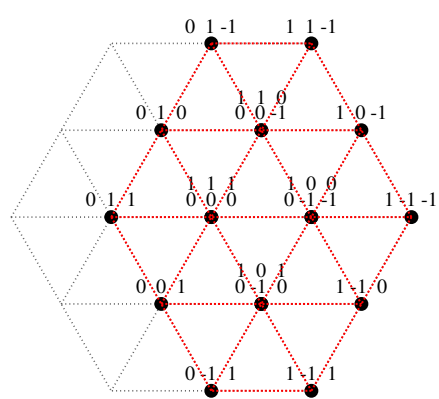

(e) ANPC - $S_{\mathrm{a} 2}-$ short



(c) NPC - $D_{\mathrm{a} 1}$ - short



(f) ANPC - $S_{\mathrm{a} 5}-$ short

Fig. 7: Space vector diagram at the corresponding short circuit fault for the three-level NPC and ANPC inverter.

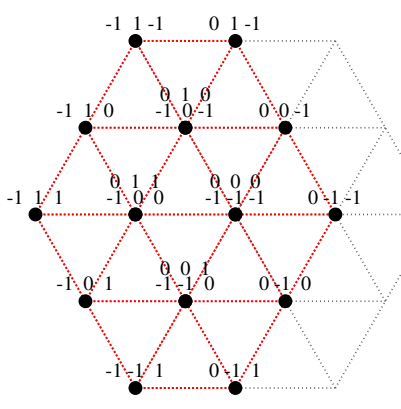

(a) NPC $S_{\mathrm{a} 1}$ - open

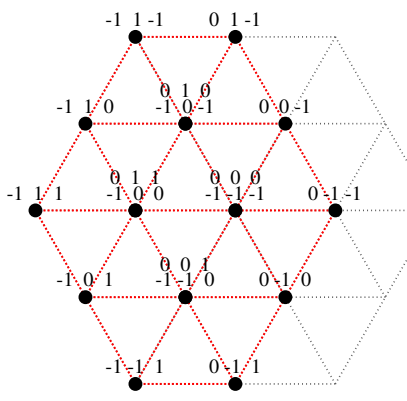

(d) ANPC $S_{\mathrm{a} 1}$ - open

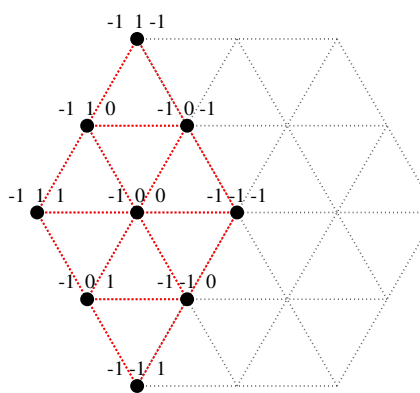

(b) NPC $S_{\mathrm{a} 2}$ - open



(e) ANPC $S_{\mathrm{a} 2}$ - open

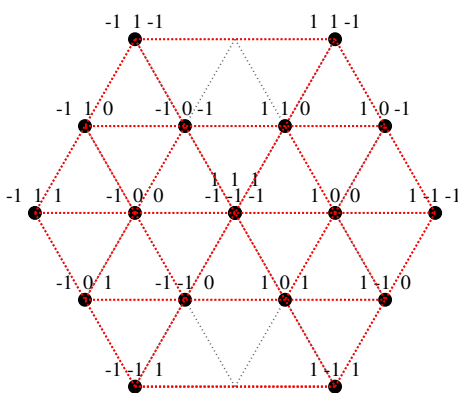

(c) NPC $D_{\mathrm{a} 1}$ - open

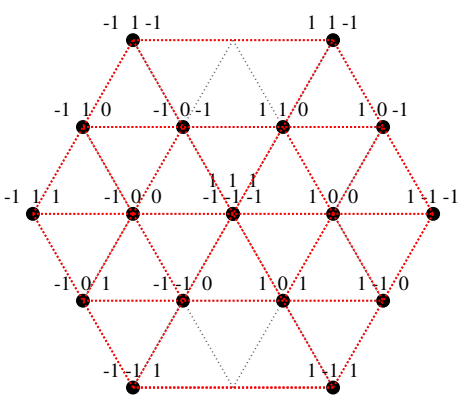

(f) ANPC $S_{\mathrm{a} 5}$ - open

Fig. 8: Space vector diagram at the corresponding open circuit fault for the three-level NPC and ANPC inverter. 
complete sectors, which in turn results in a high torque ripple, forcing the power train to stall. For the other two open circuit fault cases the space vector modulation can be adapted to single source operation or the faulty leg is operated in twolevel operation. If an active NPC inverter is used, the remaining valid states change according to Figs. 8(d) to 8(f). For an open circuit at $S_{\mathrm{a} 5}$ a complete open circuit was considered, because an open circuit of the switch would not affect the functionality of the inverter, since the body or package diode would still work. A current estimator can be utilized to detect open circuit faults, which can be used for current controlled motors or grid feeding inverter applications. When designing the current controller in direct and quadrature quantities for an interior permanent magnet machine, loop shaping is commonly used. This measure has the objective to shape the response of the system like a first order system with a bandwidth 10 times slower than the PWM-converter. Assuming a good knowledge of the plant, the current can be estimated by a discrete first order system as

$$
\underline{i}_{\mathrm{sdq}}(k)=\underline{i}_{\mathrm{sdq}}(k-1)+\alpha_{\mathrm{c}}\left(\underline{i}_{\mathrm{sdq}, \mathrm{ref}}(k)-\underline{i}_{\mathrm{sdq}}(k-1)\right)
$$

where the bandwidth $\alpha_{\mathrm{c}}$ typically equals 0.1 [32]. This estimation is accurate as long as $\frac{f_{1}}{f_{\mathrm{sw}}} \leq 0.1$. If $\frac{f_{1}}{f_{\mathrm{sw}}}$ equals 0.1 , the phase shift is $18^{\circ}$ and the amplitude error is about $2 \%$ [32]. This in turn results in an inaccurate current estimation during high transients of the current reference. Figs. 9 (a) to 9 (f) describe the simulated detection of an open circuit event for switch $S_{\mathrm{a} 2}$, occurring at $t_{\mathrm{err}}=0.2 \mathrm{~s}$, if a speed reference is applied as depicted in Fig. 9(e). The mechanical dynamics are modeled as a rotating single mass with a low inertia to speed up the simulation time. In the beginning of the fault, the current of the faulty phase is negative, meaning that the fault cannot be detected until the current becomes positive, which is the worst-case scenario. To detect a fault condition, the reference, estimated and measured current values in quadrature quantities, as can be seen in Figs. 9(c) and 9 (d), are processed as illustrated in Fig. 10.

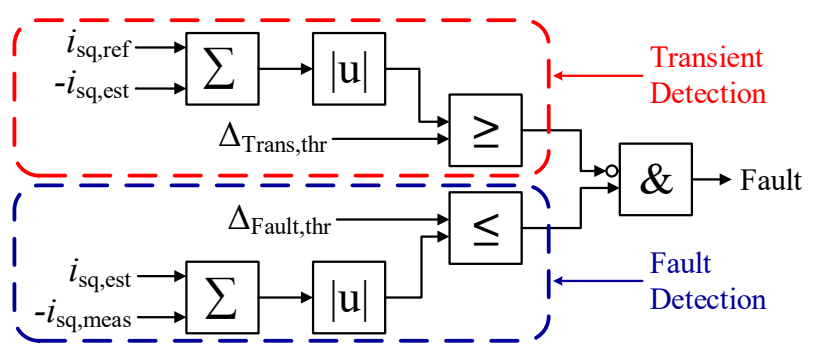

Fig. 10: Schematical fault triggering with fault and transient detection conditions.

If the difference of the measured and the estimated value exceeds a certain threshold $\left(\Delta_{\text {Fault,thr }}\right)$, a fault detection signal is activated. However, during high current transients, a current difference occurs as well, as shown in Fig. 9 f), which could be misinterpreted as an error. Therefore, a transient detection condition is added, so that the actual fault signal is just triggered during small transient conditions. From Fig. 9(f), it can be seen, that the estimated and the measured current differs substantially when applying a step in the reference, due to the sample delay of the discrete control and the bandwidth of the controller. An additional delay of the estimated current reduces the difference, but during a high transient a detection is not instantly possible. However, during small transients and steady state, the error detection time is within a few switching cycles referring to the time instant where the faulty device would start to conduct the phase current.

\section{OPEN CIRCUIT FAULT DIAGNOSIS AT STAND STILL}

As noted above, the source of an error must be localized to adapt the space vector modulation scheme properly. In this section a fault localization in form of a pulse pattern injection at standstill is introduced. It thus requires, the vehicle to stop after the detection of a fault. TABLE III(a) shows the six pulses that need to be applied for a single or multiple switching intervals and the average phase currents of the response during the zero state that must be observed.

TABLE II: Open circuit fault localization

(a) Pulse pattern

\begin{tabular}{|c|c|c|c|c|c|}
\hline Case & Pulse & $I_{a}$ & $I_{b}$ & $I_{c}$ & $\begin{array}{c}\text { Conducting } \\
\text { switches }\end{array}$ \\
\hline I & $(1,0,0) \rightarrow(0,0,0)$ & $>0$ & $<0$ & $<$ & $\begin{array}{c}S_{\mathrm{a} 1}, S_{\mathrm{a} 2}, D_{\mathrm{b} 2} \\
S_{\mathrm{b} 3}, D_{\mathrm{c} 2}, S_{\mathrm{c} 3}\end{array}$ \\
\hline II & $(0,1,0) \rightarrow(0,0,0)$ & $<0$ & $>$ & $<$ & $\begin{array}{c}D_{\mathrm{a} 2}, S_{\mathrm{a} 3}, S_{\mathrm{b} 1}, \\
S_{\mathrm{b} 2}, D_{\mathrm{c} 2}, S_{\mathrm{c} 3}\end{array}$ \\
\hline III & $(0,0,1) \rightarrow(0,0,0)$ & $<0$ & $<0$ & $>0$ & $\begin{array}{l}D_{\mathrm{a} 2}, S_{\mathrm{a} 3}, D_{\mathrm{b} 2}, \\
S_{\mathrm{b} 3}, S_{\mathrm{c} 1}, S_{\mathrm{c} 2}\end{array}$ \\
\hline IV & $(-1,0,0) \rightarrow(0,0,0)$ & $<0$ & $>0$ & $>0$ & $\begin{array}{c}S_{\mathrm{a} 3}, S_{\mathrm{a} 4}, D_{\mathrm{b} 1}, \\
S_{\mathrm{b} 2}, D_{\mathrm{c} 1}, S_{\mathrm{c} 2}\end{array}$ \\
\hline V & $(0,-1,0) \rightarrow(0,0,0)$ & $>0$ & $<$ & $>0$ & $\begin{array}{c}D_{\mathrm{a} 1}, S_{\mathrm{a} 2}, S_{\mathrm{b} 3}, \\
S_{\mathrm{b} 4}, D_{\mathrm{c} 1}, S_{\mathrm{c} 2}\end{array}$ \\
\hline VI & $(0,0,-1) \rightarrow(0,0,0)$ & $>0$ & $>0$ & $<0$ & $\begin{array}{c}D_{\mathrm{a} 1}, S_{\mathrm{a} 2}, D_{\mathrm{b} 1}, \\
S_{\mathrm{b} 2}, S_{\mathrm{c} 3}, S_{\mathrm{c} 4}\end{array}$ \\
\hline
\end{tabular}

(b) Diagnosis for phase leg a



If a response complies with the condition of the average phase currents, all conducting switches are properly functioning and the case response can be assessed as "TRUE", otherwise "FALSE" $(\neg)$. Depending on the result of the responses, the error can be localized by a combination of the 6 different responses as described in TABLE II(b). Fig. 11 shows the pulse responses for an open circuit fault at $S_{\mathrm{a} 2}$. The dashed lines mark the expected responses for Cases I and IV, where the observed average currents do not comply with the conditions in 


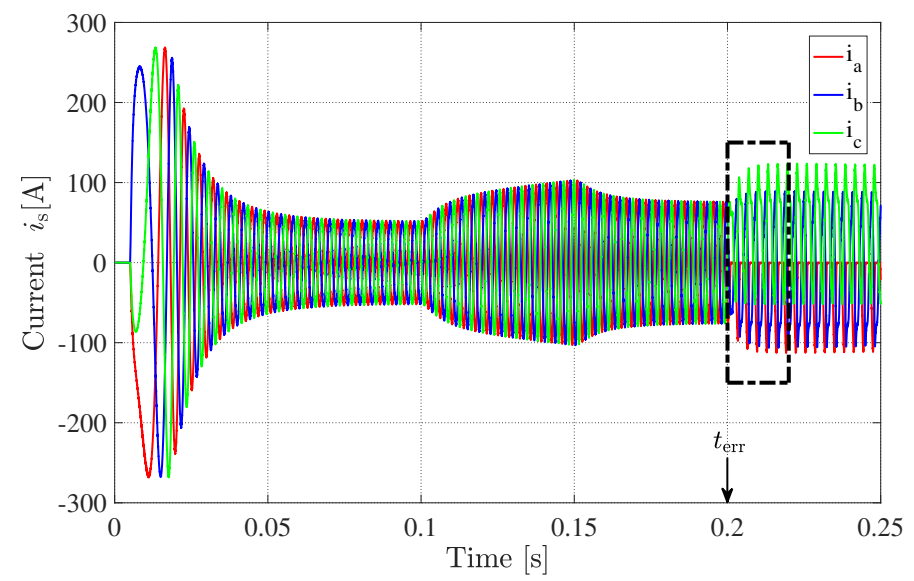

(a) Phase currents



(c) Quadrature current

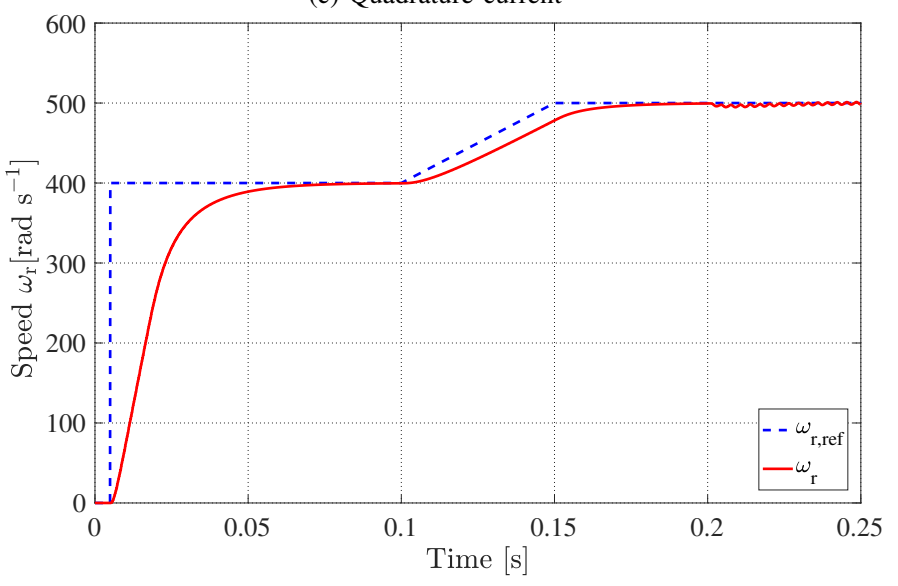

(e) Speed

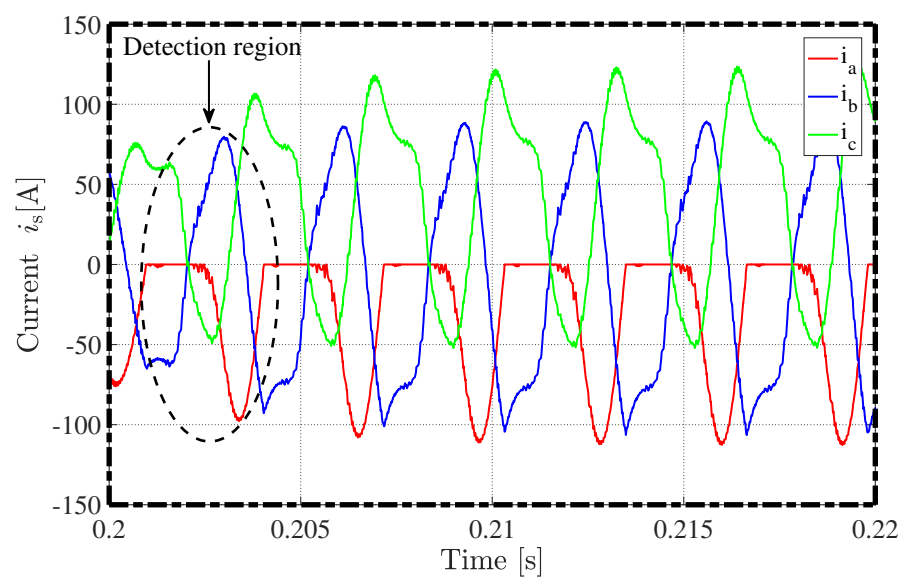

(b) Phase currents zoom



(d) Quadrature current zoom

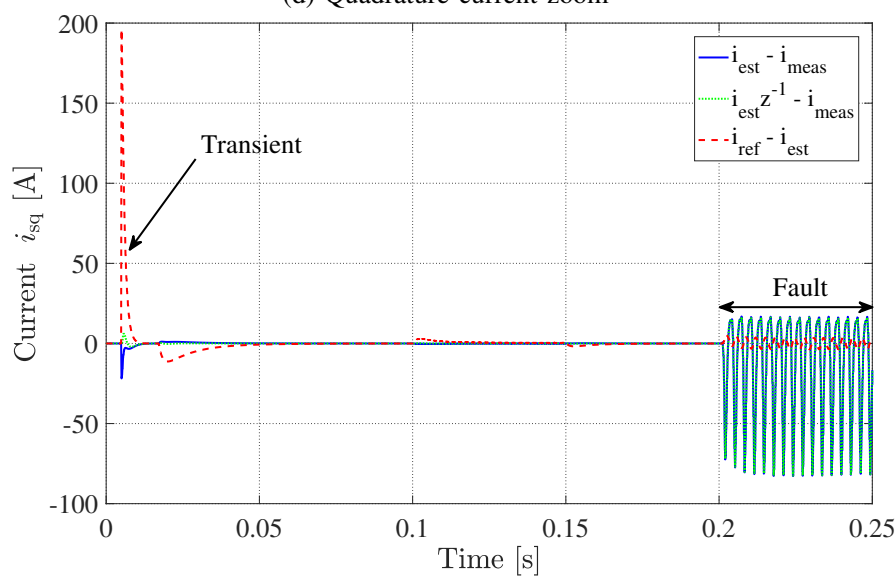

(f) Fault detection

Fig. 9: Motor currents (a)(b), quadrature current (c)(d), motor speed (e) and fault detection signal (f) for an open circuit fault at $S_{\mathrm{a} 2}$ of the NPC inverter.

TABLE II (b), while all other cases were successful. Therefore, switch $S_{\mathrm{a} 2}$ can be localized as the faulty switch. The same approach can be applied to an ANPC inverter, to check the main switches and the body/package diodes of the clamping
MOSFETs. As long as the body/package diodes of the clamping MOSFETS and the main switches $S_{x 1}$ to $S_{x 4}$ are working, the inverter can be properly operated and the phase currents do not yield any fault indications. The main difference of the 


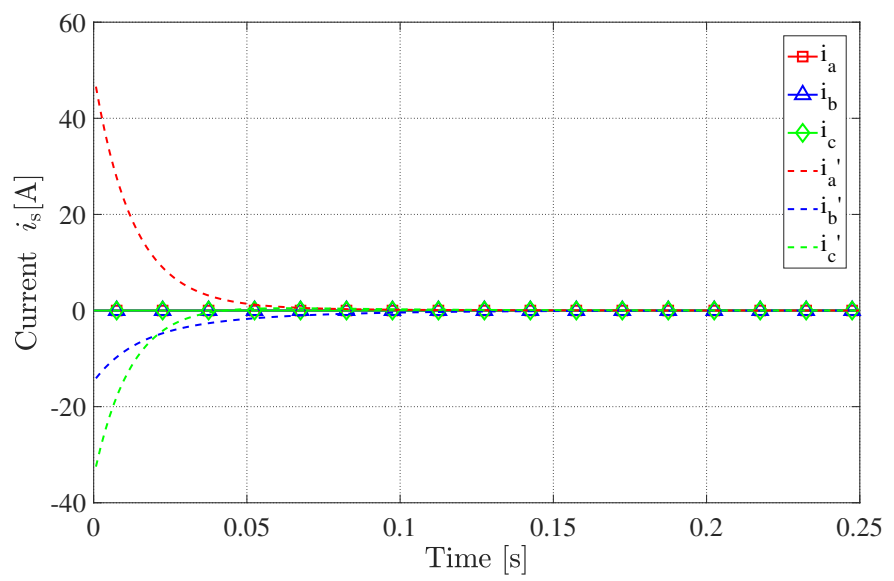

(a) I==FALSE

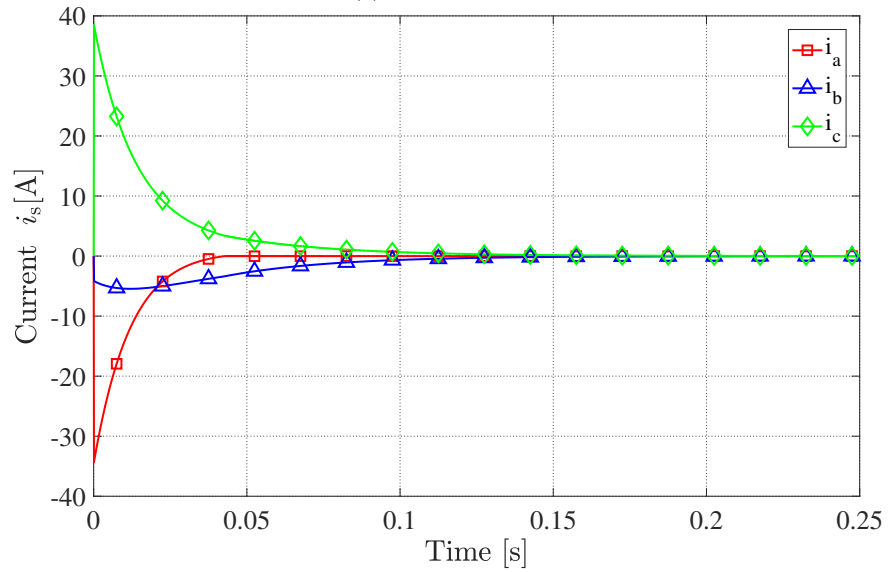

(c) $\mathrm{III}==\mathrm{TRUE}$

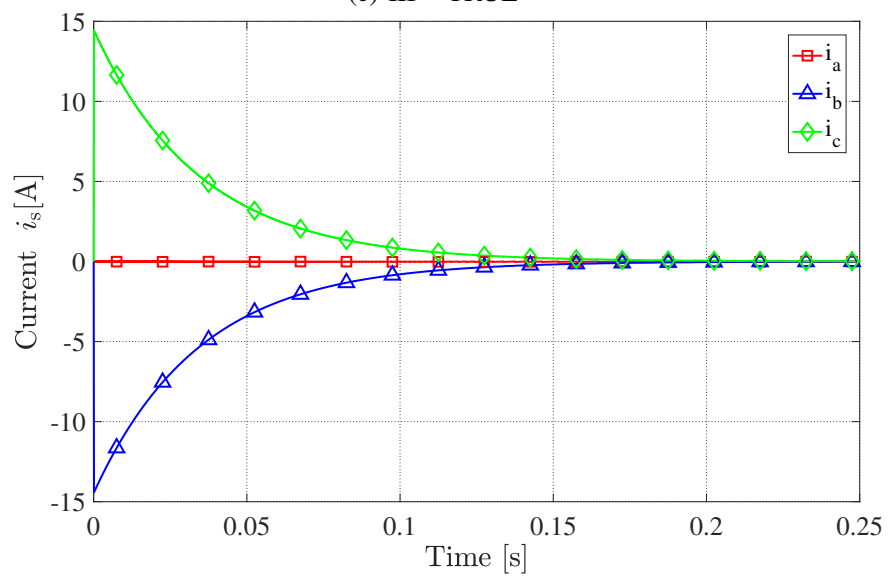

(e) $\mathrm{V}==$ FALSE

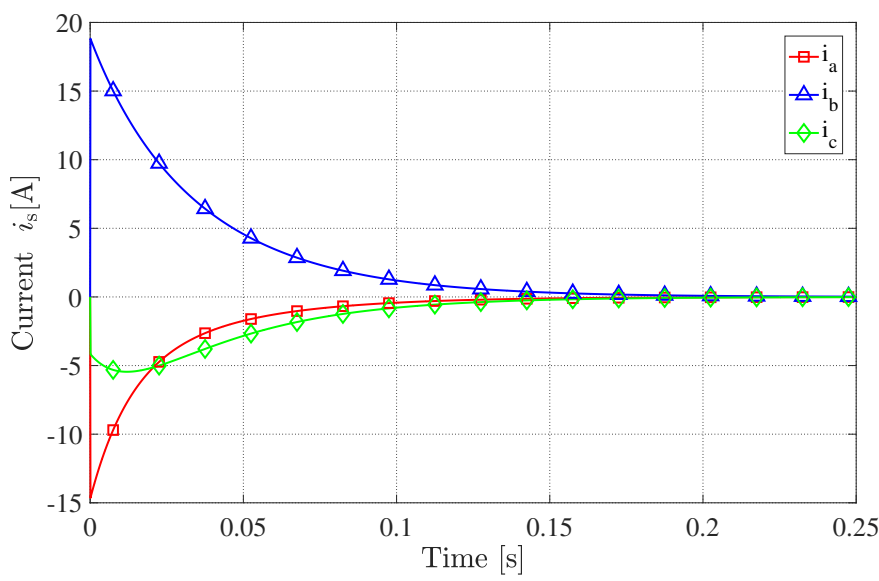

(b) $\mathrm{II}==\mathrm{TRUE}$

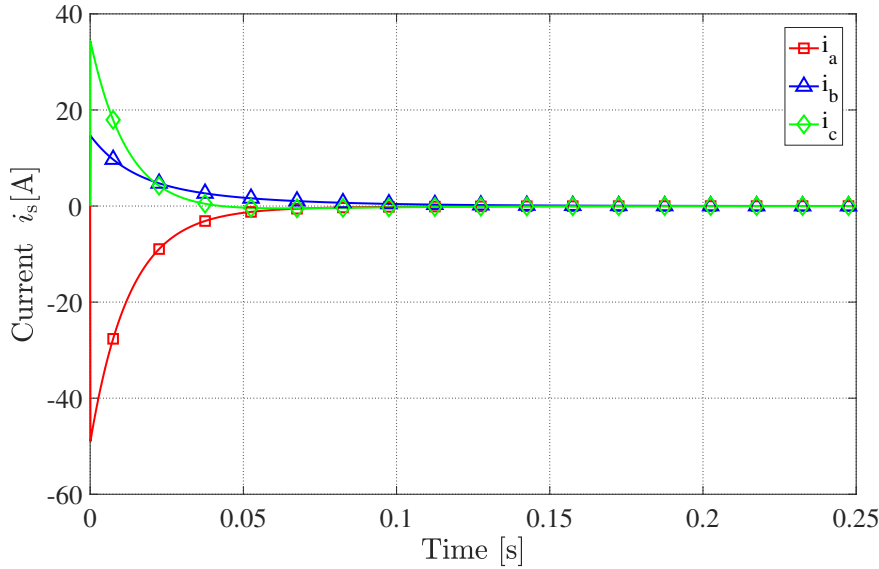

(d) IV==TRUE

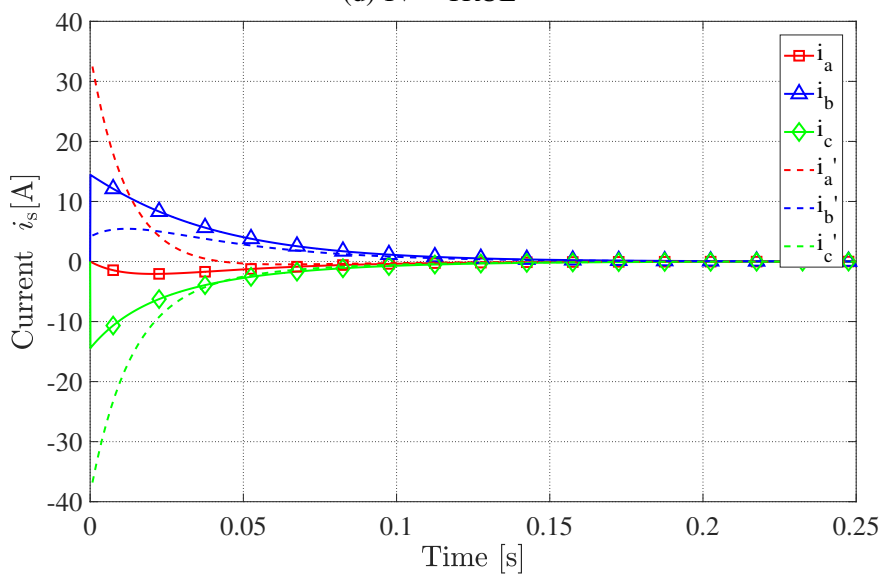

(f) $\mathrm{VI}==$ FALSE

Fig. 11: Pulse response for a localization of an open circuit fault at $S_{\mathrm{a} 2}$ for the NPC and ANPC inverter.

ANPC to the NPC inverter lies in the possibility to overcome a fault at an inner switch, for example $S_{\mathrm{a} 2}$. Therefore, the channels of the MOSFETs must be tested in reverse direction. For this purpose, a test pulse for each switch can be applied and the response according to TABLE $[\mathrm{III}$ must be observed.
Here, just one switch of the tested leg must be switched on during the zero state, which is depicted in the table with a positive $\left(0^{\mathrm{p}}\right)$ or negative $\left(0^{\mathrm{n}}\right)$ marked exponent, representing the upper and lower half leg, respectively. Fig. 12 depicts the pulse response of the clamping MOSFETs of phase leg a. Both 
are working properly, since they are able to conduct in reverse direction.

TABLE III: Open circuit fault localization at clamping MOSFETs

\begin{tabular}{ccccc}
\hline Pulse & $I_{\mathrm{a}}$ & $I_{\mathrm{b}}$ & $I_{\mathrm{c}}$ & $\begin{array}{c}\text { Broken switch } \\
(\text { if FALSE) }\end{array}$ \\
\hline$\left(0^{\mathrm{p}}, 1,1\right) \rightarrow\left(0^{\mathrm{p}}, 0,0\right)$ & $<0$ & - & - & $S_{\mathrm{a} 5}$ \\
$\left(0^{\mathrm{n}},-1,-1\right) \rightarrow\left(0^{\mathrm{n}}, 0,0\right)$ & $>0$ & - & - & $S_{\mathrm{a} 6}$ \\
$\left(1,0^{\mathrm{p}}, 1\right) \rightarrow\left(0,0^{\mathrm{p}}, 0\right)$ & $-<0$ & - & $S_{\mathrm{b} 5}$ \\
$\left(-1,0^{\mathrm{n}},-1\right) \rightarrow\left(0,0^{\mathrm{n}}, 0\right)$ & $->0$ & - & $S_{\mathrm{b} 6}$ \\
$\left(1,1,0^{\mathrm{p}}\right) \rightarrow\left(0,0,0^{\mathrm{p}}\right)$ & - & $-<0$ & $S_{\mathrm{c} 5}$ \\
$\left(-1,-1,0^{\mathrm{n}}\right) \rightarrow\left(0,0,0^{\mathrm{n}}\right)$ & - & $->0$ & $S_{\mathrm{c} 6}$ \\
\hline
\end{tabular}

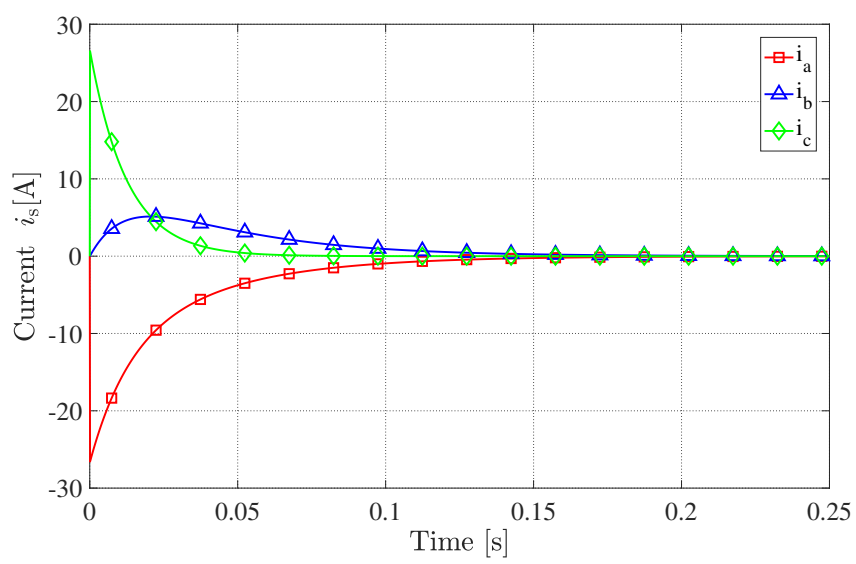

(a) I==TRUE

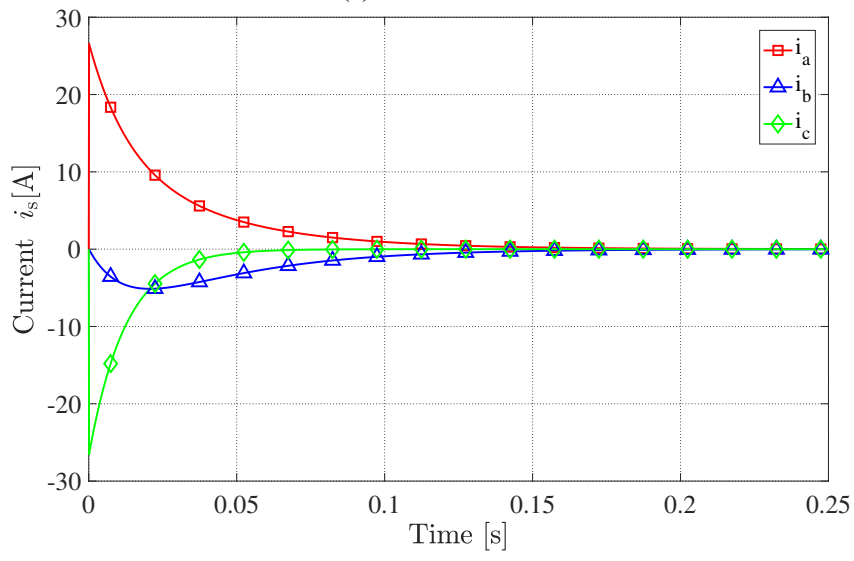

(b) II==TRUE

Fig. 12: Pulse response to test MOSFETs $S_{\mathrm{a} 5}$ (a) and $S_{\mathrm{a} 6}$ (b) in reverse direction for the ANPC inverter.

\section{ONLINE OPEN CIRCUIT DIAGNOSIS}

To localize the open circuit fault during online operation, the faulty half leg needs to be first determined and subsequently two different space vector modulation patterns are used, twolevel operation of the corresponding half leg and single battery operation. A schematic overview of the fault detection and localization for the NPC inverter can be seen in Fig. 13. To determine the faulty half leg, the average Park vector method is often used as described in [8]. It is based on the Clark transformation of the average values of the phase currents, yielding a nonzero value at fault condition. The method, however, cannot be used to accurately determine the faulty switch of the half leg. The average value of the phase currents can be written as

$$
I_{x, \text { avg }}=\frac{1}{T_{\mathrm{s}}} \int_{t_{0}}^{t_{0}+T_{\mathrm{s}}} i_{x} \mathrm{dt},
$$

where the integral part stands for a charge, which can be divided into a positive charge as

$$
Q_{x, \mathrm{p}}=\int+i_{x, \mathrm{p}} \mathrm{dt}
$$

and a negative charge as

$$
Q_{x, \mathrm{n}}=\int-i_{x, \mathrm{n}} \mathrm{dt}
$$

The direction of the phase current yields the consideration of a positive and negative charge, described as

$$
i_{x, \mathrm{n}}=\left\{\begin{array}{ll}
0 ; & i_{x}>0 \\
i_{x} ; & i_{x}<=0
\end{array},\right.
$$

and

$$
i_{x, \mathrm{p}}=\left\{\begin{array}{ll}
i_{x} ; & i_{x}>0 \\
0 ; & i_{x}<=0
\end{array} .\right.
$$

Immediately after the detection of the fault, as can be seen in the scheme, the polar phase charges should be calculated according to (11) and (12) for a certain time duration, where the minimum yields the faulty half leg according to TABLEIV

TABLE IV: Open circuit fault localization

\begin{tabular}{cc}
\hline Minimum & Broken half leg \\
\hline$Q_{\mathrm{a}, \mathrm{p}}$ & $S_{\mathrm{a} 1} \& S_{\mathrm{a} 2} \& D_{\mathrm{a} 1} / S_{\mathrm{a} 5}$ \\
$Q_{\mathrm{a}, \mathrm{n}}$ & $S_{\mathrm{a} 3} \& S_{\mathrm{a} 4} \& D_{\mathrm{a} 2} / S_{\mathrm{a} 6}$ \\
$Q_{\mathrm{b}, \mathrm{p}}$ & $S_{\mathrm{b} 1} \& S_{\mathrm{b} 2} \& D_{\mathrm{b} 1} / S_{\mathrm{b} 5}$ \\
$Q_{\mathrm{b}, \mathrm{n}}$ & $S_{\mathrm{b} 3} \& S_{\mathrm{b} 4} \& D_{\mathrm{b} 2} / S_{\mathrm{b} 6}$ \\
$Q_{\mathrm{c}, \mathrm{p}}$ & $S_{\mathrm{c} 1} \& S_{\mathrm{c} 2} \& D_{\mathrm{c} 1} / S_{\mathrm{c} 5}$ \\
$Q_{\mathrm{c}, \mathrm{n}}$ & $S_{\mathrm{c} 3} \& S_{\mathrm{c} 4} \& D_{\mathrm{c} 2} / S_{\mathrm{c} 6}$ \\
\hline
\end{tabular}

Fig. 14 (a) shows an example, when an open circuit fault occurs at $t_{\mathrm{err}}=0.2 \mathrm{~s}$ at $S_{\mathrm{a} 2}$, as depicted in Fig. 9. Depending on the accuracy of the charges, an acceptable result is already achieved after about $3 \mathrm{~ms}$ to $10 \mathrm{~ms}$, which corresponds to 1 to 3 electrical periods. It can be seen, that $Q_{\mathrm{a}, \mathrm{p}}$ remains zero, which indicates a fault at the positive half leg of phase a. Next, the space vector modulator should be adapted to 2-level operation, meaning the avoidance of the zero state for phase a, as emphasized in green in Fig. 14 b). If the control of the current is regained, the clamping diode is broken. Otherwise, the space vector modulator is subsequently adapted only to small vectors. This causes the available torque to be compromised, which may cause a braking torque to be applied to the drive train. 




Fig. 13: Schematic overview of the online fault localization of an open circuit fault of the NPC inverter.

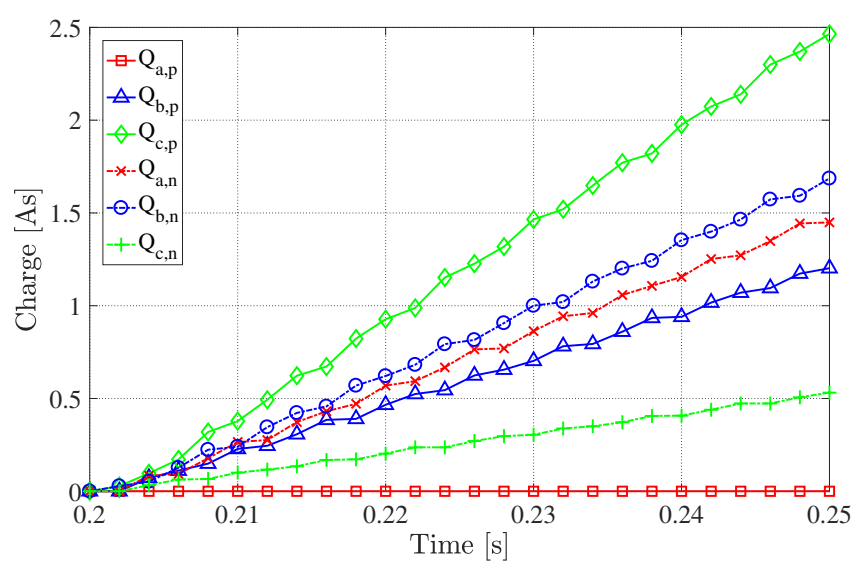

(a) Phase charges

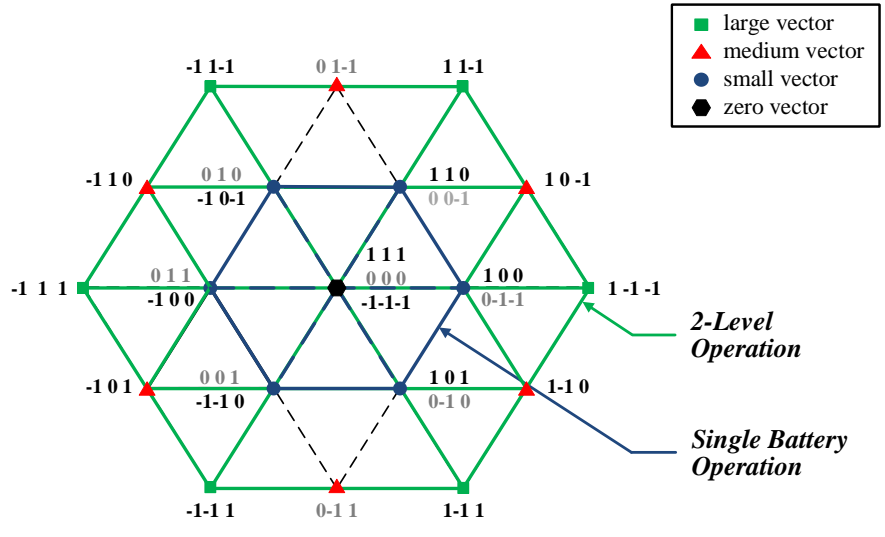

(b) Adapted space vector modulation

Fig. 14: Phase charges in case of an open circuit fault at $S_{\mathrm{a} 2}$ (a) and corresponding single battery and two-level space vector modulation of phase a (b).

\section{A. Open Circuit Fault - $D_{\mathrm{a} 1}$}

Fig. 15 shows the detection and localization of an open circuit fault of $D_{\mathrm{a} 1}$. The fault occurs at $t_{\mathrm{err}}=0.2 \mathrm{~s}$, as marked in Fig. 15 (a), which shows the three-phase currents. As can be seen in Fig. 15(b), during fault operation the difference of the estimated and measured current yields a nonzero os- cillating distortion. The threshold, $\Delta_{\text {Fault,thr }}$, could be chosen to be a few amps, so that the fault can be detected almost instantaneous by the relation of the estimated and measured current according to Fig. 10. After a successful detection, the positive and negative phase charges are calculated, as shown in Fig. 15 (c). Already after $6 \mathrm{~ms}$ to $10 \mathrm{~ms}$, depending on the accuracy of the calculated charges, an open circuit fault at the positive half leg of phase a can be localized. Subsequently, two-level operation is started at $t_{2 \text { level }}=0.21 \mathrm{~s}$ to finally regain current control, which is achieved $15 \mathrm{~ms}$ after fault inception. Since the current control is successfully regained, the clamping diode $D_{\mathrm{a} 1}$ must be faulty. If an ANPC inverter is used, an open circuit of $S_{\mathrm{a} 5}$ or its antiparellel diode does not lead to a loss of the current controllability, since the remaining MOSFET in the clamping path works bidirectional. However, the commutation path is affected. Therefore, it might be advisable to run a standstill diagnosis for the ANPC inverter from time to time.

\section{B. Open Circuit Fault - $S_{\mathrm{a} 1}$}

In this case, shown in Fig. 16, an open circuit fault at $S_{\mathrm{a} 1}$ occurs at $t_{\text {err }}=0.2 \mathrm{~s}$. The same procedure as above is applied. It can be seen in Fig. 16 b) that the difference of the estimated and measured current exceeds even $50 \mathrm{~A}$, which is about 5 times higher than for the broken diode in the previous case. Therefore, it should be noted that the threshold $\Delta_{\text {Fault,thr }}$ must be chosen in manner to comply with all fault cases. Thus, the threshold for this case should be kept as before, which is still suitable for an instantaneous detection, but it provides a smaller margin for disturbances, for example, signal noises and torque ripple due to the slot harmonics. Also here, at $t_{2 l e v e l}=0.21 \mathrm{~s}$, two-level operation is started. However, for this fault the twolevel operation is not successful in regaining current control. Therefore, the space vector modulation is changed to single battery operation at $t_{\mathrm{sbat}}=0.22 \mathrm{~s}$, which compromises the available torque, as can be seen in Fig. 5 This, in turn, might lead to a short braking torque, if the power-train was operating at high load and high speed. Furthermore, it can be observed that the output currents' amplitude has increased by factor 2 , because the output voltage is halved. Nevertheless, it can be seen, that current control is regained, which indicates an open circuit fault at $S_{\mathrm{a} 1}$. In this case, the procedure's outcome does not differ from a common to an active NPC inverter. 


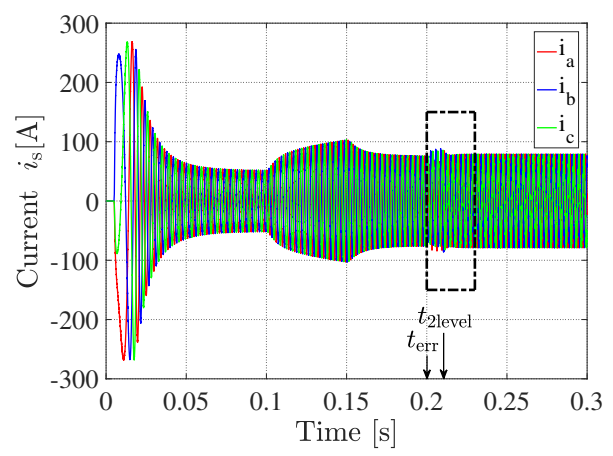

(a) Phase currents

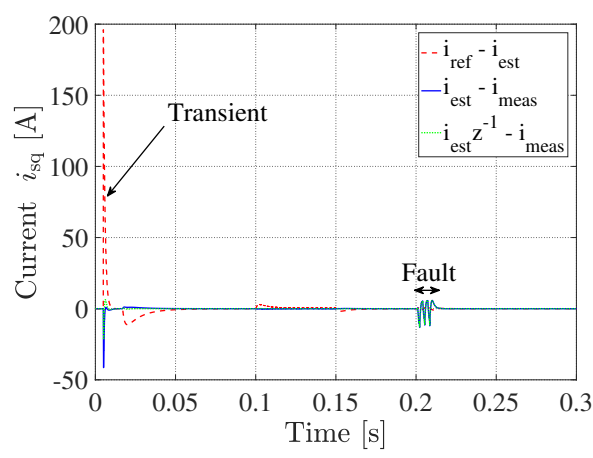

(b) Fault detecion

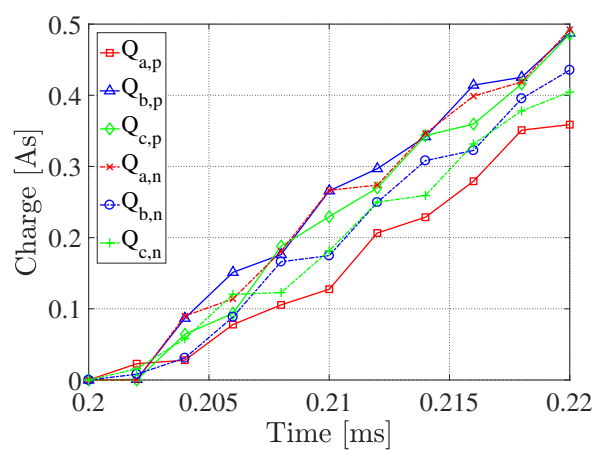

(c) Phase charges

Fig. 15: Localization of an open circuit fault at $D_{\mathrm{a} 1}$ for the NPC inverter.

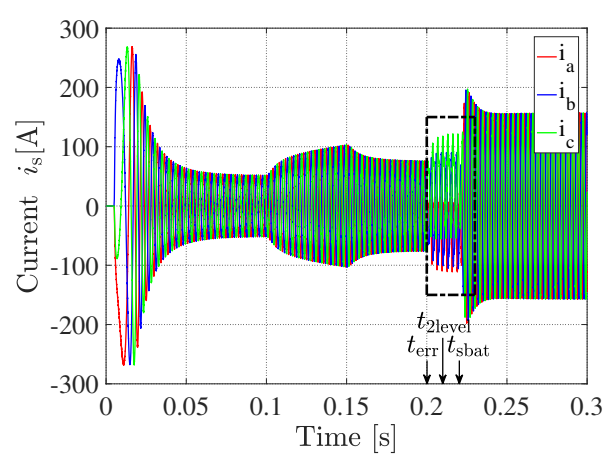

(a) Phase currents

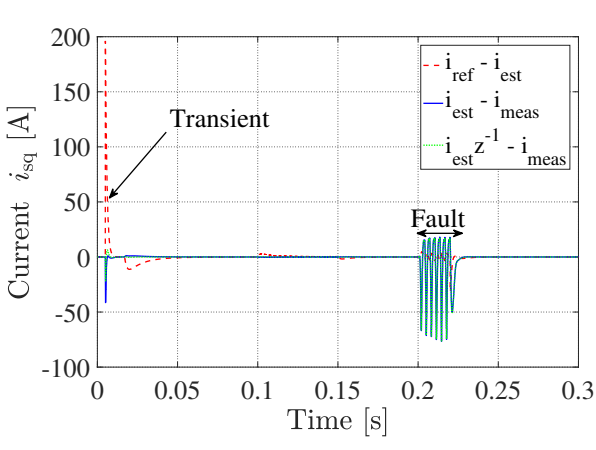

(b) Fault detection

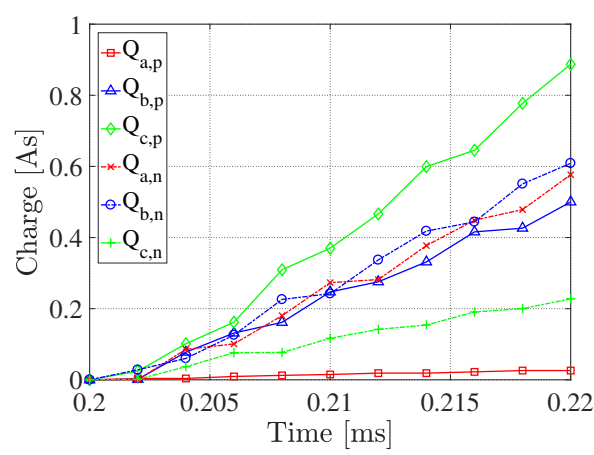

(c) Phase charges

Fig. 16: Localization of an open circuit fault at $S_{a 1}$ for the NPC inverter.

\section{Open Circuit Fault - $S_{\mathrm{a} 2}$}

As seen from section III, the differentiation between an active and common NPC inverter is essential since the active NPC inverter, containing MOSFETs in the clamping path, is able to be operated in single battery operation in the case of an open circuit fault at an inner switch. Therefore, the last fault case shows an open circuit fault at $S_{\mathrm{a} 2}$, occurring at $t_{\text {err }}=0.2 \mathrm{~s}$, as shown in Figs. 17 and 18 for the NPC and the ANPC inverter, respectively. The same procedure as before is followed and both inverters show the same behavior until single battery operation is applied. As can be seen in Figs. 17 b) and 18, b), an instantaneous fault detection is easily achieved due to the high three-phase current distortion. Next, the phase charges are calculated as can be seen in Figs. 177(c) and 18 (c). Already after $3 \mathrm{~ms}$ to $10 \mathrm{~ms}$, the phase charges yield a minimum of $Q_{\mathrm{a}, \mathrm{p}}$, as expected, which indicates a fault at the positive half leg of phase a. Afterwards, two level operation and single battery operation are applied at $t_{2 \text { level }}=0.21 \mathrm{~s}$ and $t_{\text {sbat }}=0.22 \mathrm{~s}$, respectively. Regarding the NPC inverter, neither in two-level nor in single battery operation is current control regained, which indicates an open circuit fault of $S_{\mathrm{a} 2}$. Consequently, the NPC inverter has to shut down, as seen in Fig. 17 a), and the power train has to stall, braking mechanically, shown in Fig. 17)(d). On the contrary, if an ANPC inverter is used, two-level operation does not show an effect either, but the fault can be overcome and current control is regained by single battery operation, as can be seen from the current and speed plots in Fig. 18 This is due to the fact, that the clamping MOSFET $S_{\mathrm{a} 6}$ works bidirectional. This is one of the major advantages of an ANPC inverter compared to an NPC inverter, in particular for an automotive application.

\section{NPC INVERTER TEST BENCH}

To verify the theory assumptions and simulation results above, a simple, open circuit fault test procedure is conducted on a test bench, which can be seen in Fig. 19.a). The test-bed comprises a common NPC inverter, shown in Fig. 19(b), to drive a two-pole induction machine. A field oriented control is implemented, similar as described in Section II, although an induction machine instead of an interior permanent magnet machine is used. Nevertheless, the observer theorem, given in 99, remains valid since the current controller is designed using loop shaping [32]. For safety reasons and simplicity, all measurements are conducted with a nominal DC link voltage of $60 \mathrm{~V}$, which is sufficient to prove the concept validity. For the implementation of the pulse pattern injection and an adapted space vector modulation, a PWM signal generator is used. An introduced open circuit fault at $S_{\mathrm{a} 1}$ should be handled. The test procedure is divided into three parts: the fault detection, the fault localization and the fault mitigation. 


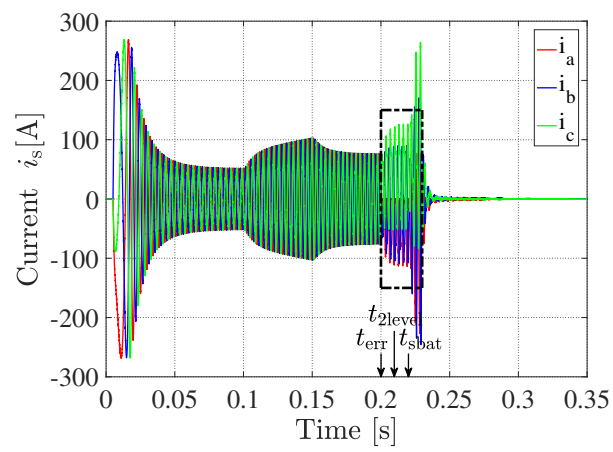

(a) Phase currents

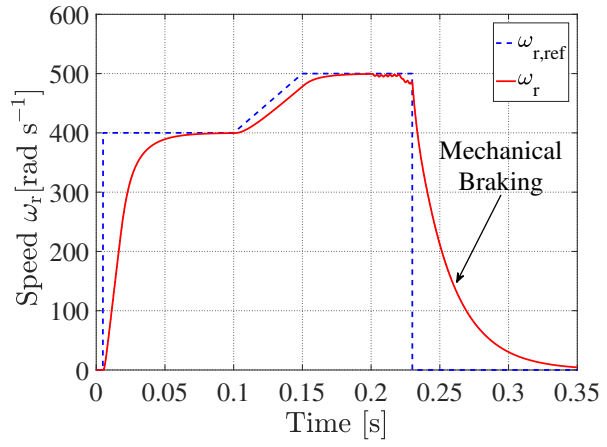

(d) Speed

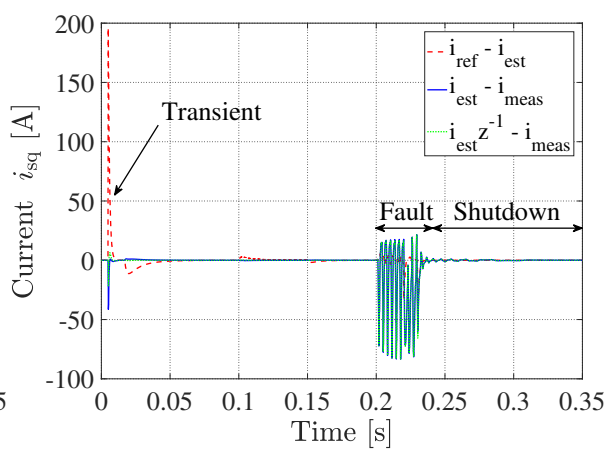

(b) Fault detection

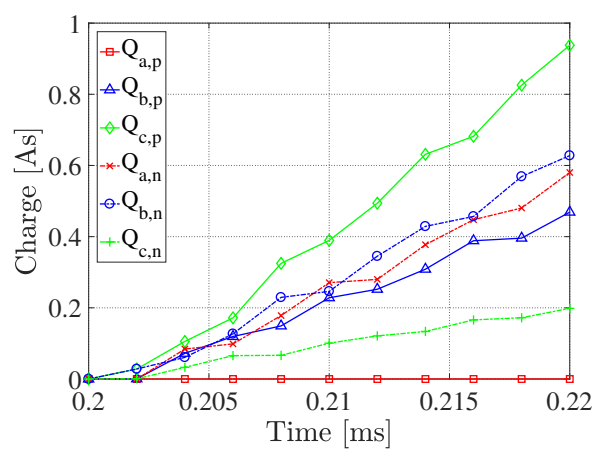

(c) Phase charges

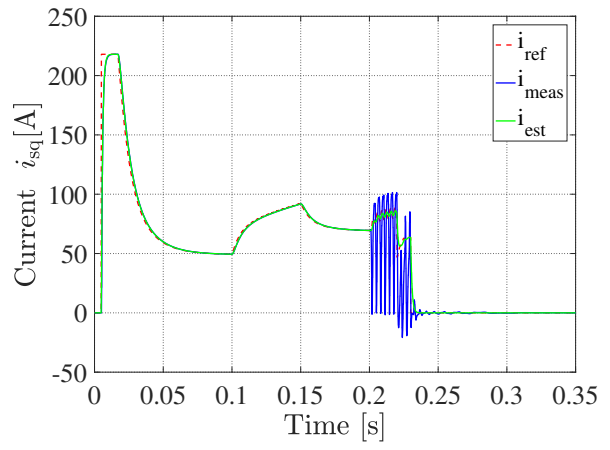

(e) Quadrature current

Fig. 17: Localization of an open circuit fault at $S_{\mathrm{a} 2}$ for the NPC inverter.



(a) Phase currents

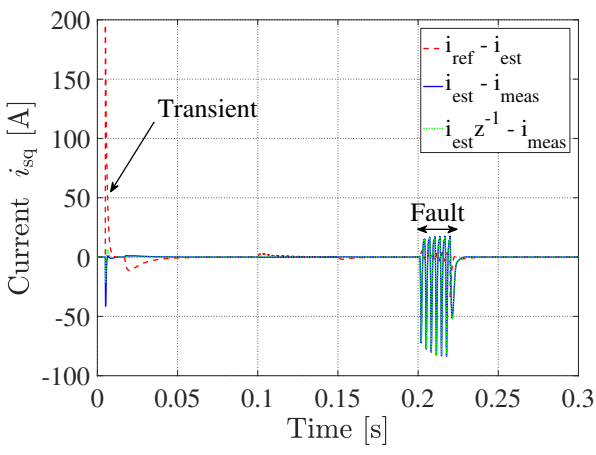

(b) Fault detection

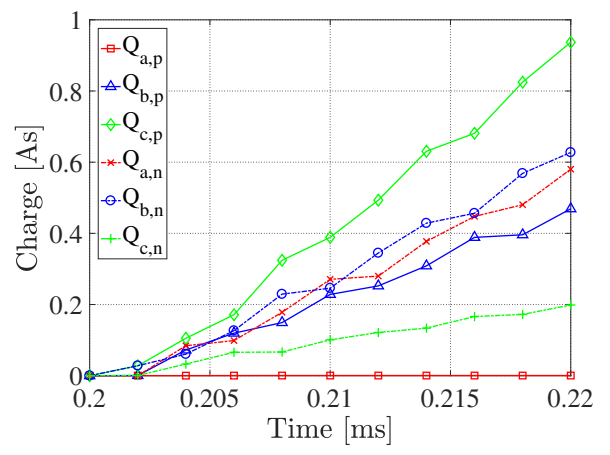

(c) Phase charges

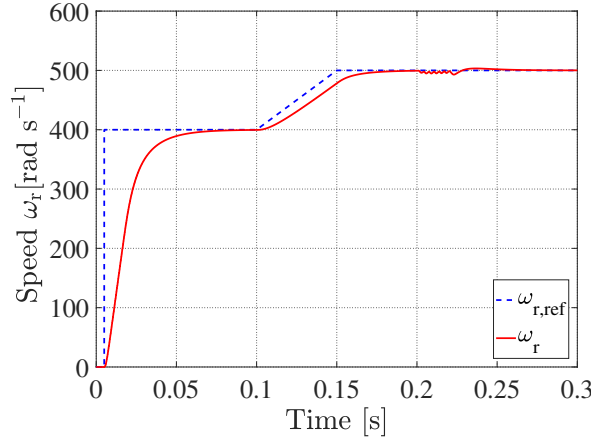

(d) Speed

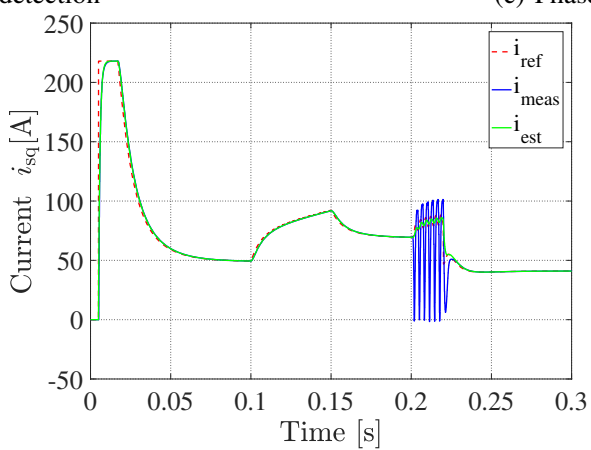

(e) Quadrature current

Fig. 18: Localization of an open circuit fault at $S_{\mathrm{a} 2}$ for the ANPC inverter. 


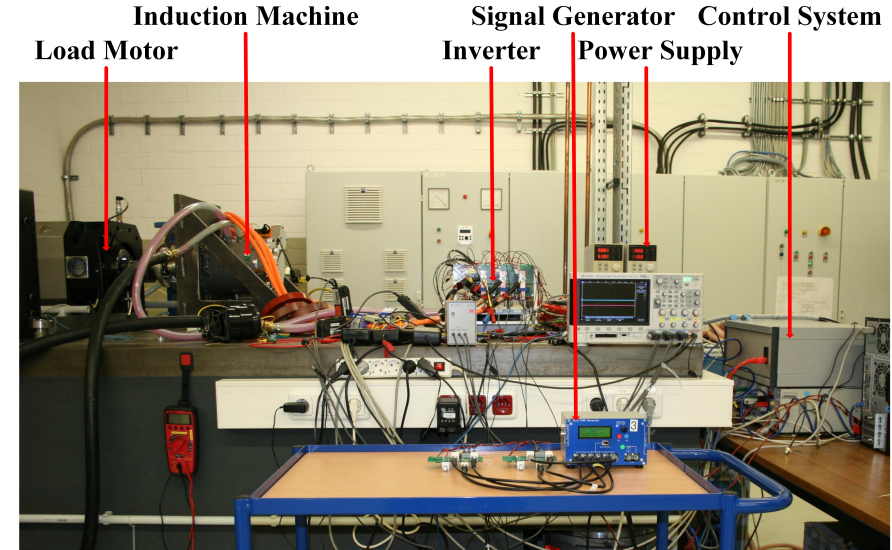

(a) Test-bed



(b) Inverter

Fig. 19: Test bench (a) and NPC inverter (b).

\section{A. Fault Detection}

At first, the machine's three-phase currents are controlled to have a peak value of $10 \mathrm{~A}$ and a fundamental frequency of $17 \mathrm{~Hz}$, as shown in Fig. 20.a). Since the machine is unloaded, $i_{\mathrm{sd}}$ equals the phase currents' peak value (amplitude-invariant) at steady state, whereas $i_{\mathrm{sq}}$ is roughly zero, as can be seen in Fig. 20(b). The rotational speed reaches about 505 to $510 \mathrm{rpm}$, which equals the synchronous speed of $510 \mathrm{rpm}$. At steady state, an open circuit fault at switch $S_{\mathrm{a} 1}$ is introduced at $t_{\text {err }}=0.2 \mathrm{~s}$ by disconnecting the corresponding fibre optic cable, that transmits the gate signal. From the three-phase current and dq-current plots, it can be seen that the currents are distorted during fault operation. Similar as in the simulations, the faulty phase leg does not conduct the current in forward direction, which in turn distorts and increases the peak current of the remaining phases. Comparing the currents with the simulation results seen in Fig. 16(a), a similar characteristic can be observed, but the phase shift of the currents is altered, since the machine type differs and the operating point is shifted from the field weakening to the constant torque region, though these changes do not change the effectiveness of the detection algorithm. Depending on the threshold for triggering a fault signal, the fault detection time could be within a few $\mu$ s up to $20 \mathrm{~ms}$ (a third of an electrical period). But since the peak-to-peak ripple of the q-current at steady state is within a band of $1 \mathrm{~A}$, which should not be misinterpreted as a fault, an almost instant detection of a few $\mu$ s is easily achieved, if setting a threshold criteria $\Delta_{\text {Fault,thr }}$ of $2 \mathrm{~A}$ as $\left|i_{\mathrm{sq}, \text { est }}-i_{\mathrm{sq}, \text { meas }}\right| \leq 2 A$.

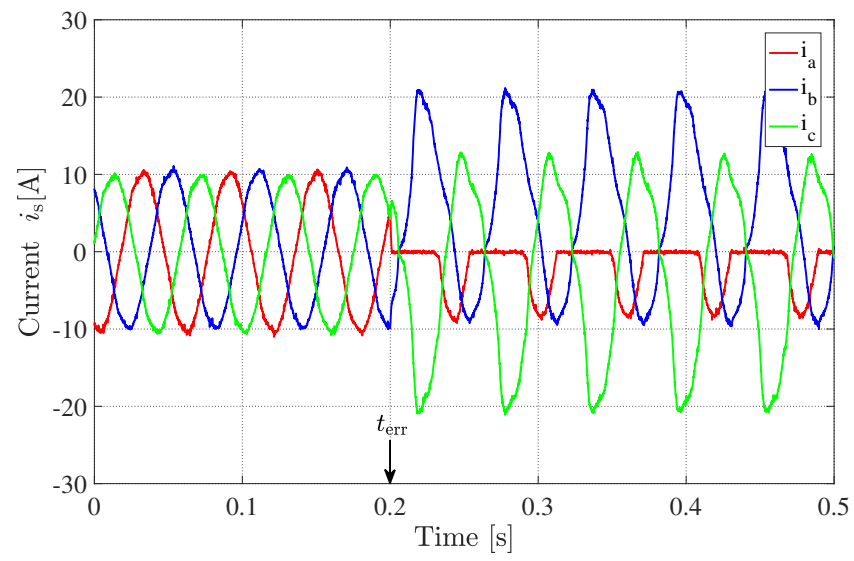

(a) Phase currents

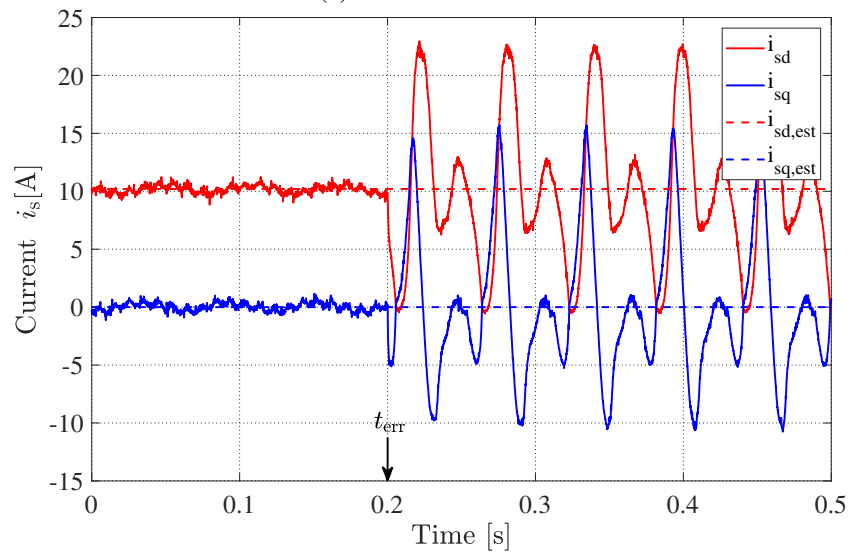

(b) Fault detection

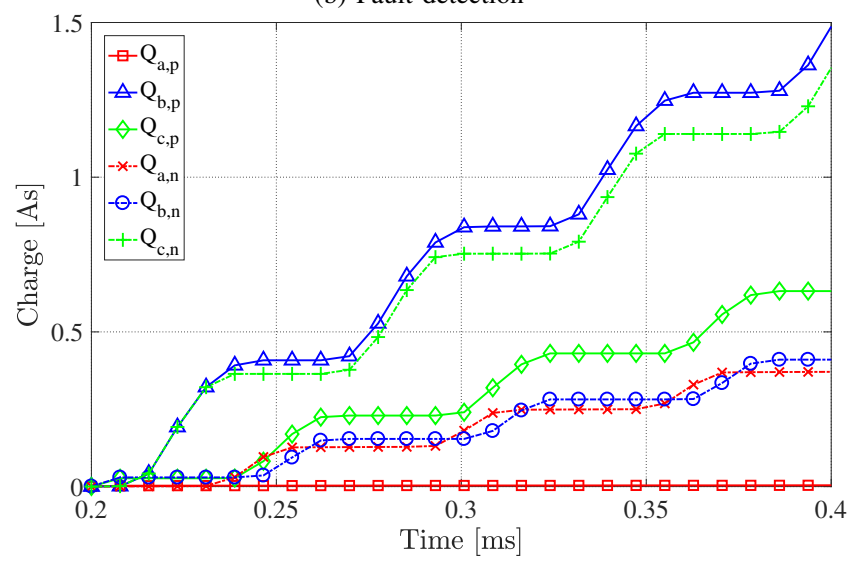

(c) Phase charges

Fig. 20: Measured detection of an open circuit fault at $S_{\mathrm{a} 1}$ for the NPC inverter. 


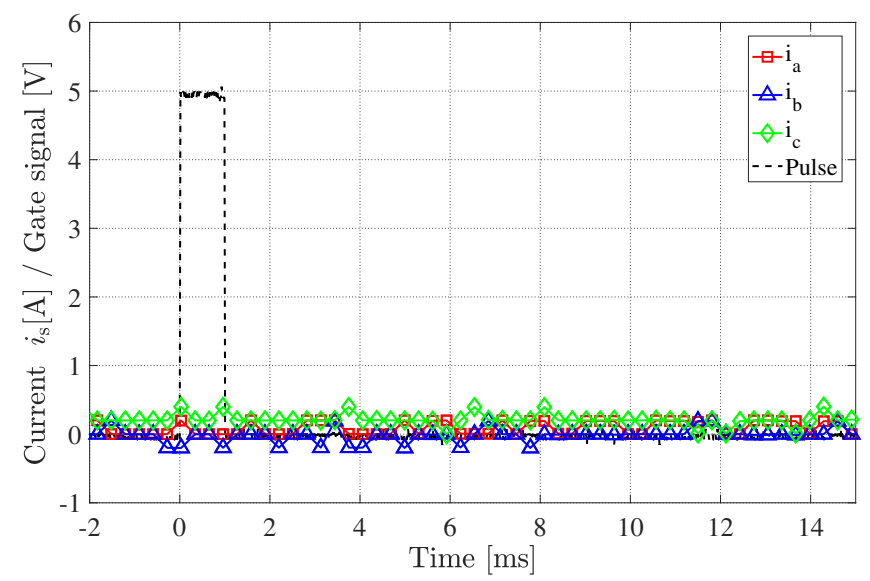

(a) I==FALSE

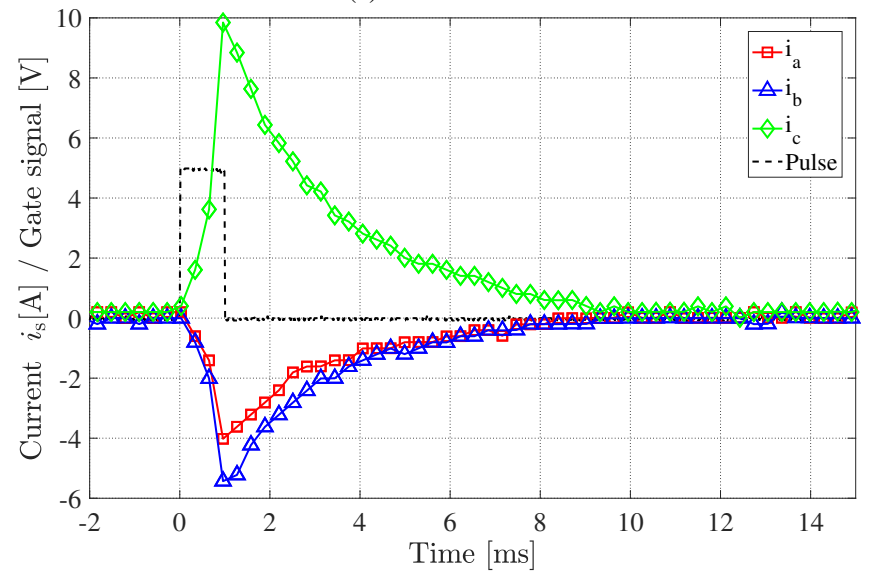

(c) $\mathrm{III}==\mathrm{TRUE}$

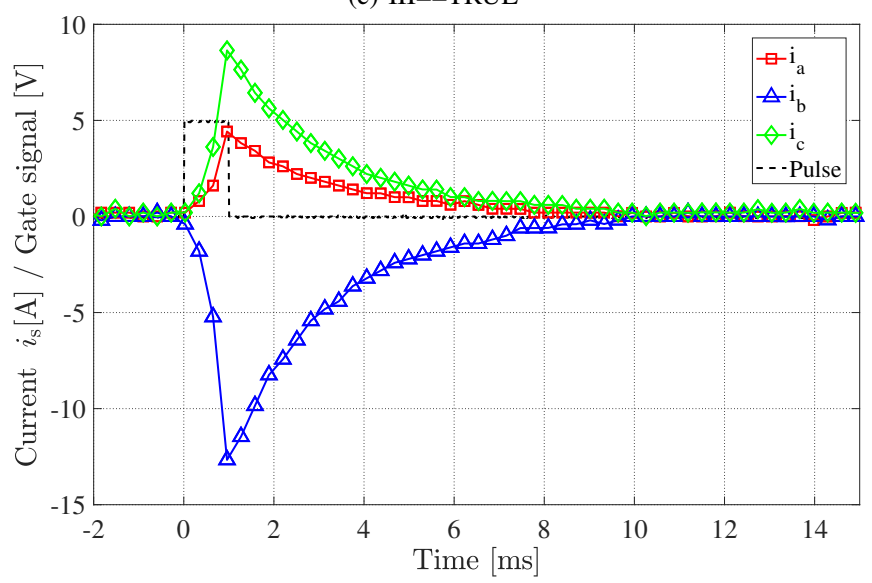

(e) V==TRUE

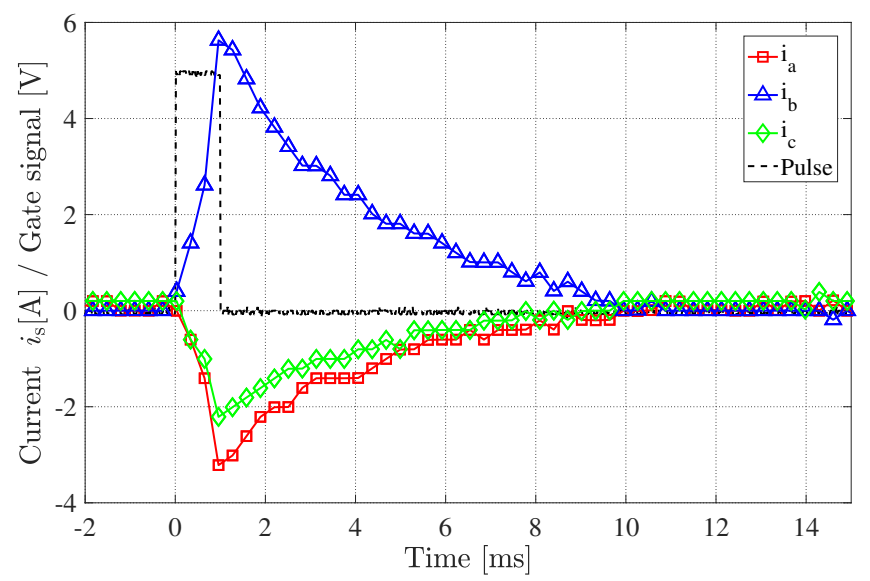

(b) $\mathrm{II}==\mathrm{TRUE}$

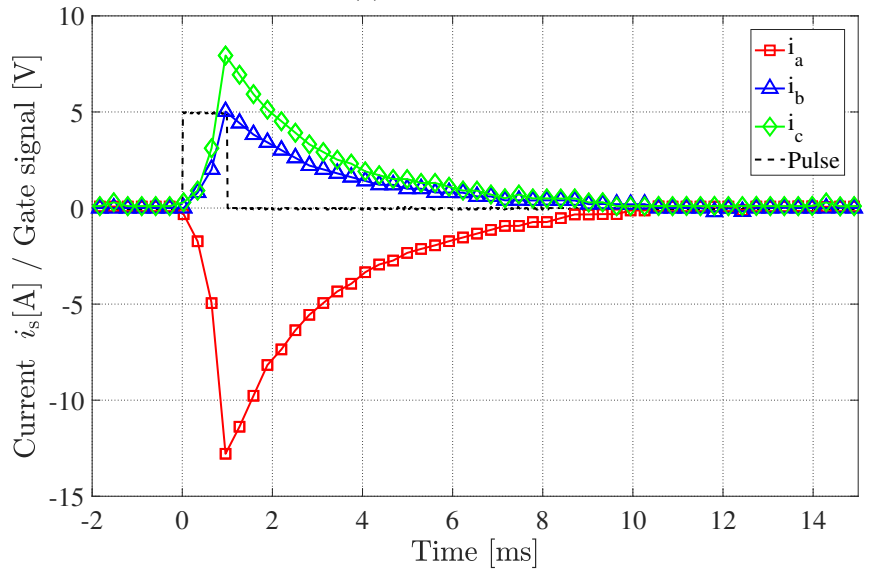

(d) IV==TRUE

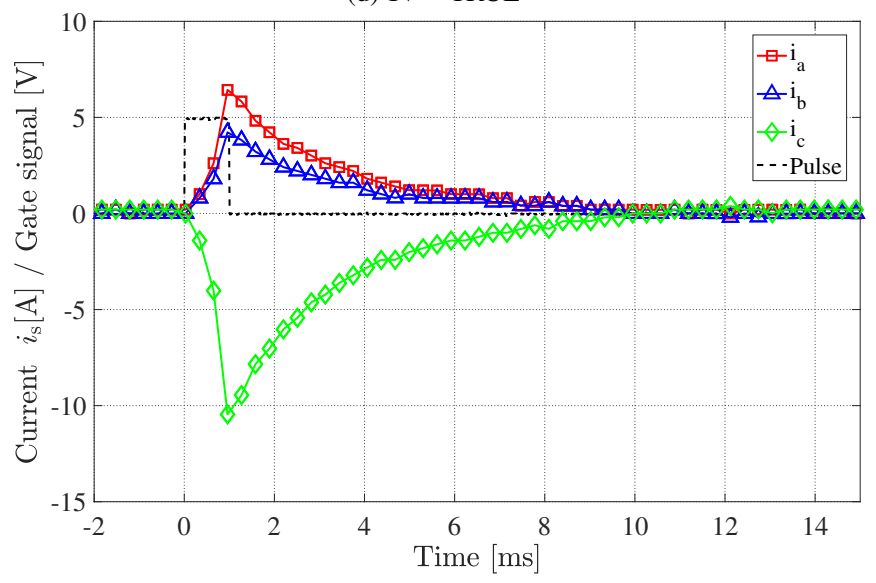

(f) $\mathrm{VI}==$ TRUE

Fig. 21: Measured pulse responses for a localization of an open circuit fault at $S_{\mathrm{a} 1}$ for the NPC inverter.

If the online localization method would be applied, the phase charges according to (10)-(14) are calculated, as can be seen in Fig. 20(c). The minimum of charge $Q_{\mathrm{a}, \mathrm{p}}$ indicates a fault at the positive half leg of phase a. It can be seen, that the algorithm converges to a reliable result after one electrical period, similar as in the simulations, of about $60 \mathrm{~ms}$.

\section{B. Pulse Pattern Injection}

After a successful fault detection, the motor is stopped and the open circuit fault is localized by the response of the injected pulse pattern, as can be seen in Fig 21. Since the DC link voltage is limited to 60 Volt, the current derivative is low. Therefore, a pulse duration of $1 \mathrm{~ms}$ is chosen to 
achieve an acceptable magnitude of the current responses so that these can be post-processed. In the simulations, a pulse duration of $100 \mu \mathrm{s}$ was used, which was already sufficient since the DC link voltage was chosen to be $400 \mathrm{~V}$ and the motor inductance was less than, in comparison, the induction machine. Regarding the responses, it can be seen that the three-phase response currents for Case I are zero, whereas all remaining cases show nonzero current responses with the expected polarity. Therefore, according to TABLE[I] an open circuit fault at switch $S_{\mathrm{a} 1}$ can be identified.

\section{Single Source Operation}

An open circuit fault at switch $S_{\mathrm{a} 1}$ means that the inverter can still be operated in single battery operation. Therefore, the inverter is restarted, utilizing just the negative DC link voltage, as can be seen in Fig 22. The magnitude of the phase currents

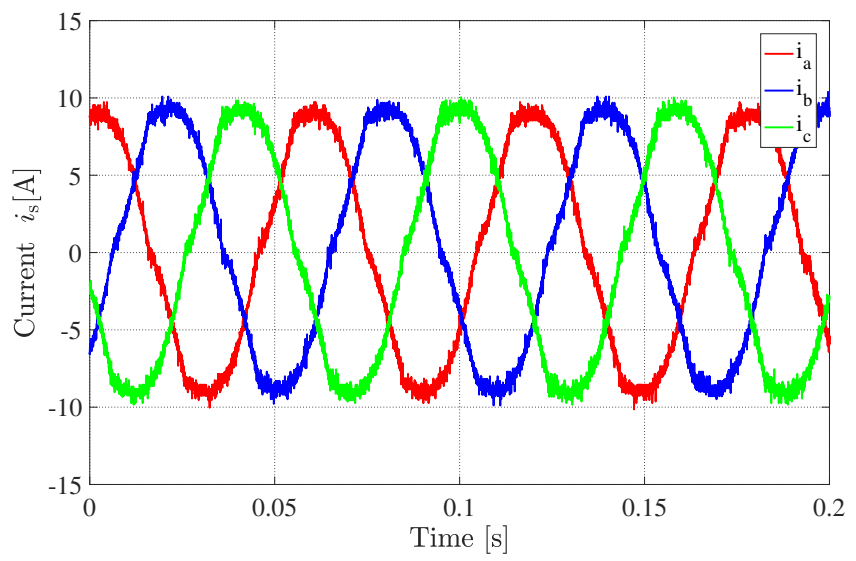

(a) Phase currents



(b) PWM output voltage

Fig. 22: Single source operation of the NPC inverter with utilization of the negative DC link in the case of an open circuit fault at $S_{\mathrm{a} 1}$ : three-phase stator currents (a) and zoomed time interval with switched phase voltage (b).

can still be controlled to $10 \mathrm{~A}$ as shown in Fig.22(a). Fig.22(b) shows a short time interval of $1 \mathrm{~ms}$, so that the output voltage of one phase can be seen. As expected, the output voltage is just switched between the neutral point and the negative DC link.

\section{CONCLUSION}

This paper has shown the possibilities and limitations of a "limp home" function of a three-level NPC and ANPC inverter with a neutral point connection in the case of single, open and short circuit switch faults and the failure of one battery supply, due to an external short circuit or an internal battery supply fault. The main focus is on a software-based detection and localization of open circuit faults of the inverter's switches. Therefore, a new open circuit fault detection method using a simple current estimator and two new fault localization techniques are presented and verified using simulations and experiments. The fault detection time is a fraction of an electrical period, i.e. almost instantaneous up to a third of an electrical period, referring to the time instant the faulty device would start to conduct. The detection algorithm can be applied to variable speed drives during steady state and transients, as long as these are complying with the bandwidth of the current controller. One of the fault localization algorithms can be applied at standstill. It is based on the pulse response of six injected pulses to check the main switches and clamping diodes. In case an ANPC inverter is used, each MOSFET must be tested in reverse direction by an additional pulse. The second fault localization algorithm can be applied online during operation. The phase currents can be used to localize the faulty half leg and the adaption of the space vector modulation scheme as two-level and single battery operation yield the location of the faulty switch. It was found that an ANPC inverter is able to overcome all shown single faults, even without stopping the vehicle, whereas a common NPC inverter loses current controllability in the case of an open circuit at an inner switch, whereby the drive train will stall. From the simulations and experiments, it was seen that the localization of the faulty half leg requires one electrical period, which might be quite long at low speeds. Hence, it would be more suitable to stop the car and localize the fault during stand still. However, at high speeds, the fault can be quickly localized during operation. Nevertheless, a switch or diode fault in the clamping path of the ANPC inverter does not lead to a loss of the controllability, but the current commutation is affected. For this reason, a stand still analysis should be conducted at certain time intervals. Finally, it can be said that the demonstrated principles can easily be implemented in NPC or ANPC inverter driven vehicles without needing additional hardware. In case of a fault, the vehicle driver would not need to call for a towing service, instead the vehicle could easily be driven to the next service station or even be used for some days with limited, but acceptable performance. Furthermore, the algorithms could be adapted for various multi-level inverter topologies and multi-fault cases could be considered, since redundant power electronic systems are gaining more interest. Regarding the online open circuit localization algorithm, future challenges lie in the determination of its robustness with respect to parameter mismatches and measurement disturbances. Additionally, the detection and localization in terms of the triggering time 
relative to the accuracy for various operating points of the drive train, especially during rated torque and field weakening region, should be investigated.

\section{REFERENCES}

[1] A. L. Julian and G. Oriti, "A comparison of redundant inverter topologies to improve voltage source inverter reliability," IEEE Transactions on Industry Applications, vol. 43, no. 5, pp. 1371-1378, Sept 2007.

[2] K. K. Gupta, A. Ranjan, P. Bhatnagar, L. K. Sahu, and S. Jain, "Multilevel inverter topologies with reduced device count: A review," IEEE Transactions on Power Electronics, vol. 31, no. 1, pp. 135-151, Jan 2016.

[3] A. Nabae, I. Takahashi, and H. Akagi, "A new neutral-point-clamped pwm inverter," IEEE Transactions on Industry Applications, vol. IA-17, no. 5, pp. 518-523, Sept 1981.

[4] A. Bubert, S. Lim, and R. W. D. Doncker, "Comparison of 2-level b6c and 3-level npc inverter topologies for electric vehicles," in 2017 IEEE Southern Power Electronics Conference (SPEC), Dec 2017, pp. 1-6.

[5] A. Kersten, E. Grunditz, and T. Thiringer, "Efficiency of active threelevel and five-level npc inverters compared to a two-level inverter in a vehicle," in 2018 20th European Conference on Power Electronics and Applications (EPE'18 ECCE Europe), Sep. 2018, pp. P.1-P.9.

[6] M. Laumen, M. Schubert, A. Bubert, A. Lamprecht, and R. W. D. Doncker, "Optimized space vector modulation for dc-link balancing in three-level neutral-point-clamped inverters for electric drives," in 2017 IEEE 12th International Conference on Power Electronics and Drive Systems (PEDS), Dec 2017, pp. 1,135-1,140.

[7] U. M. Choi, H. G. Jeong, K. B. Lee, and F. Blaabjerg, "Method for detecting an open-switch fault in a grid-connected npc inverter system,' IEEE Transactions on Power Electronics, vol. 27, no. 6, pp. 2726-2739, June 2012.

[8] M. B. Abadi, A. M. S. Mendes, and S. M. A. Cruz, "Three-level npc inverter fault diagnosis by the average current park's vector approach,' in 2012 XXth International Conference on Electrical Machines, Sept 2012, pp. $1893-1898$.

[9] J. Lee, T. Kim, J. Lee, and D. Hyun, "A novel fault detection of an openswitch fault in the npc inverter system," in IECON 2007 - 33rd Annual Conference of the IEEE Industrial Electronics Society, Nov 2007, pp. $1565-1569$.

[10] U. M. Choi, J. S. Lee, F. Blaabjerg, and K. B. Lee, "Open-circuit fault diagnosis and fault-tolerant control for a grid-connected npc inverter," IEEE Transactions on Power Electronics, vol. 31, no. 10, pp. 7234 7247, Oct 2016.

[11] H. H. Lee, P. Q. Dzung, T. P. Hoa, L. M. Phuong, and N. X. Bac, "Fault detection using ann for three-level npc inverter fed induction motor drive," in TENCON 2010 - 2010 IEEE Region 10 Conference, Nov 2010, pp. 2148-2153.

[12] I. Abari, A. Lahouar, M. Hamouda, J. B. H. Slama, and K. AlHaddad, "Fault detection methods for three-level npc inverter based on dc-bus electromagnetic signatures," IEEE Transactions on Industrial Electronics, vol. 65, no. 7, pp. 5224-5236, July 2018.

[13] H. K. Ku, W. S. Im, J. M. Kim, and Y. S. Suh, "Fault detection and tolerant control of 3-phase npc active rectifier," in 2012 IEEE Energy Conversion Congress and Exposition (ECCE), Sept 2012, pp. 45194524.

[14] H. K. Ku and J. M. Kim, "Multiple open-switch faults detection and faults tolerant method of three-level three-phase npc active rectifier," in IECON 2013 - 39th Annual Conference of the IEEE Industrial Electronics Society, Nov 2013, pp. 1062-1067.

[15] X. Ge, J. Pu, B. Gou, and Y. C. Liu, "An open-circuit fault diagnosis approach for single-phase three-level neutral-point-clamped converters," IEEE Transactions on Power Electronics, vol. 33, no. 3, pp. 2559-2570, March 2018
[16] J. He and N. A. O. Demerdash, "An on-line diagnostic method for open-circuit switch faults in npc multilevel converters," in 2016 IEEE Energy Conversion Congress and Exposition (ECCE), Sept 2016, pp. $1-7$.

[17] T. Kim, W. Lee, and D. Hyun, "Detection method for open-circuit fault in neutral-point-clamped inverter systems," IEEE Transactions on Industrial Electronics, vol. 56, no. 7, pp. 2754-2763, July 2009.

[18] K. Ma and F. Blaabjerg, "Modulation methods for three-level neutralpoint-clamped inverter achieving stress redistribution under moderate modulation index," IEEE Transactions on Power Electronics, vol. 31, no. 1, pp. 5-10, Jan 2016.

[19] A. Lewicki, Z. Krzeminski, and H. Abu-Rub, "Space-vector pulsewidth modulation for three-level npc converter with the neutral point voltage control," IEEE Transactions on Industrial Electronics, vol. 58, no. 11, pp. 5076-5086, Nov 2011.

[20] G. I. Orfanoudakis, M. A. Yuratich, and S. M. Sharkh, "Analysis of dclink capacitor current in three-level neutral point clamped and cascaded h-bridge inverters," IET Power Electronics, vol. 6, no. 7, pp. 1376-1389, August 2013.

[21] S. Mukherjee, S. Giri, and S. Banerjee, "A flexible discontinuous modulation scheme with hybrid capacitor voltage balancing strategy for three-level npc traction inverter," IEEE Transactions on Industrial Electronics, pp. 1-1, 2018.

[22] N. Celanovic and D. Boroyevich, "A comprehensive study of neutralpoint voltage balancing problem in three-level neutral-point-clamped voltage source pwm inverters," IEEE Transactions on Power Electronics, vol. 15, no. 2, pp. 242-249, Mar 2000.

[23] C. Li, T. Yang, P. Kulsangcharoen, G. L. Calzo, S. Bozhko, C. Gerada, and P. Wheeler, "A modified neutral-point balancing space vector modulation technique for three-level neutral point clamped converters in high speed drives," IEEE Transactions on Industrial Electronics, pp. $1-1,2018$.

[24] C. Q. Xiang, C. Shu, D. Han, B. K. Mao, X. Wu, and T. J. Yu, "Improved virtual space vector modulation for three-level neutralpoint-clamped converter with feedback of neutral-point voltage," IEEE Transactions on Power Electronics, vol. 33, no. 6, pp. 5452-5464, June 2018.

[25] H. Zhang, L. Yang, S. Wang, and J. Puukko, "Common-mode emi noise modeling and reduction with balance technique for three-level neutral point clamped topology," IEEE Transactions on Industrial Electronics, vol. 64, no. 9, pp. 7563-7573, Sept 2017.

[26] F. Liu, K. Xin, and Y. Liu, "An adaptive discontinuous pulse width modulation (dpwm) method for three phase inverter," in 2017 IEEE Applied Power Electronics Conference and Exposition (APEC), March 2017, pp. 1467-1472.

[27] X. Zhou and S. Lu, "A simple zero-sequence voltage injection method to balance the neutral-point potential for three-level npc inverters," in 2018 IEEE Applied Power Electronics Conference and Exposition (APEC), March 2018, pp. 2471-2475.

[28] M. Uno and K. Tanaka, "Influence of high-frequency charge-discharge cycling induced by cell voltage equalizers on the life performance of lithium-ion cells," IEEE Transactions on Vehicular Technology, vol. 60, no. 4, pp. 1505-1515, May 2011.

[29] A. Bessman, R. Soares, S. Vadivelu, O. Wallmark, P. Svens, H. Ekstrm, and G. Lindbergh, "Challenging sinusoidal ripple-current charging of lithium-ion batteries," IEEE Transactions on Industrial Electronics, vol. 65 , no. 6, pp. 4750-4757, June 2018.

[30] E. Grunditz, Design and Assessment of Battery Electric Vehicle Powertrain, with Respect to Performance, Energy Consumption and Electric Motor Thermal Capability, ser. Doktorsavhandlingar vid Chalmers tekniska högskola. Ny serie, no:. Institutionen för energi och miljö, Elteknik, Chalmers tekniska högskola,, 2016, 229.

[31] O. Josefsson, Investigation of a Multilevel Inverter for Electric Vehicle Applications, ser. Doktorsavhandlingar vid Chalmers tekniska högskola. Ny serie, no:. Institutionen för energi och miljö, Elteknik, Chalmers tekniska högskola,, 2015, 146. 
[32] L. Harnefors, Control of variable-speed drives. Applied Signal Processing and Control, Department of Electronics, Mälardalen University, 2002 .

[33] J. Pou, D. Boroyevich, and R. Pindado, "New feedforward spacevector pwm method to obtain balanced ac output voltages in a threelevel neutral-point-clamped converter," IEEE Transactions on Industrial Electronics, vol. 49, no. 5, pp. 1026-1034, Oct 2002.

[34] D. Andrea, Battery management systems for large lithium ion battery packs. Artech house, 2010.

[35] X. Hu, D. Cao, and B. Egardt, "Condition monitoring in advanced battery management systems: Moving horizon estimation using a reduced electrochemical model," IEEE/ASME Transactions on Mechatronics, vol. 23, no. 1, pp. 167-178, Feb 2018.

[36] X. Li and Z. Wang, "A novel fault diagnosis method for lithium-ion battery packs of electric vehicles," Measurement, vol. 116, pp. 402 411, 2018.

[37] J. Gallardo-Lozano, E. Romero-Cadaval, M. I. Milanes-Montero, and M. A. Guerrero-Martinez, "Battery equalization active methods," Journal of Power Sources, vol. 246, pp. 934-949, 2014.

[38] Z. Ye, Y. Xu, X. Wu, G. Tan, X. Deng, and Z. Wang, "A simplified pwm strategy for a neutral-point-clamped (npc) three-level converter with unbalanced dc links," IEEE Transactions on Power Electronics, vol. 31, no. 4, pp. 3227-3238, April 2016.

[39] X. Wu, G. Tan, G. Yao, C. Sun, and G. Liu, "A hybrid pwm strategy for three-level inverter with unbalanced dc links," IEEE Journal of Emerging and Selected Topics in Power Electronics, vol. 6, no. 1, pp 1-15, March 2018.

[40] K. Oberdieck, S. Schuch, and R. W. DeDoncker, "Short circuit detection using the gate charge characteristic for trench/fieldstop-igbts," in 2016 18th European Conference on Power Electronics and Applications (EPE'16 ECCE Europe), Sept 2016, pp. 1-10.

[41] A. K. Jain and V. T. Ranganathan, " $v_{C E}$ sensing for igbt protection in npc three level converterscauses for spurious trippings and their elimination," IEEE Transactions on Power Electronics, vol. 26, no. 1, pp. 298-307, Jan 2011.

[42] D. Sadik, J. Colmenares, G. Tolstoy, D. Peftitsis, M. Bakowski, J. Rabkowski, and H. Nee, "Short-circuit protection circuits for siliconcarbide power transistors," IEEE Transactions on Industrial Electronics, vol. 63, no. 4, pp. 1995-2004, April 2016.

[43] Y. K. Priya and M. V. Kumar, "Analysis of various switch faults of the three level neutral point clamped inverter feeding induction motor drive," in 2016 2nd International Conference on Advances in Electrical, Electronics, Information, Communication and Bio-Informatics (AEEICB), Feb 2016, pp. 580-586.



Anton Kersten received the B.Eng. and the M.Sc. degree in electrical engineering with a major in electric power engineering from the University of Applied Science RheinMain in 2015 and the University of Technology Chalmers in 2017, respectively. Since October 2017 he is with the division of electric power engineering working within the field of multilevel inverter for vehicles' powertrain, while he is pursuing the $\mathrm{Ph} . \mathrm{D}$. degree.

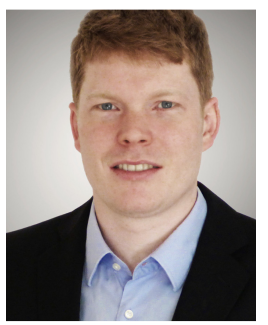

Karl Oberdieck received the B. Sc. and M. Sc degree in electrical engineering from RWTH Aachen University, Germany, in 2011 and 2013, respectively. From 2014 to 2018, he worked for the powerelectronics research group at the Institute for Power Electronics and Electrical Drives (ISEA). His research topics include modeling and development of high-frequency instruments and techniques for measurements and mitigation of electromagnetic emissions in power electronic systems. Since 2019 he works at Robert Bosch $\mathrm{GmbH}$ in Reutlingen, where he develops high-volt packaging solutions.

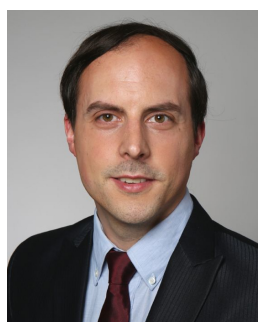

Andreas Bubert received the B.Sc. degree in business administration and the Diploma degree in electrical engineering from RWTH Aachen University, Aachen, Germany, in 2012 and 2013, respectively. $\mathrm{He}$ is a researcher with the Institute for Power Electronics and Electrical Drives, RWTH Aachen University. Since 2016, he has been the head of the Electrical Drives Department. His research interests are in the field of drivetrain optimization and bearing currents of electrical machines in automotive applications.

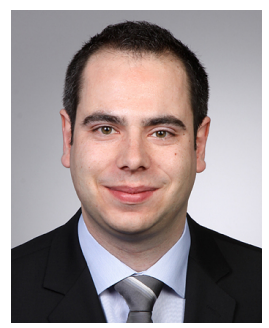

Markus Neubert received the Diploma degree in electrical engineering from RWTH Aachen University, Aachen, Germany, in 2012. Since October 2012, he has been with the Institute for Power Electronics and Electrical Drives (ISEA), RWTH Aachen University, where he is currently chief engineer. His research interests are in the field of power electronics and control.

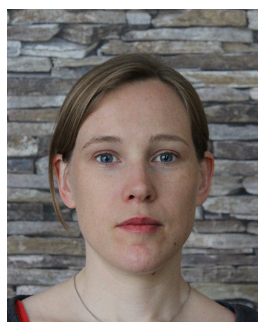

Emma Arfa Grunditz received her M.Sc. degree in 2009 and her Ph.D. degree in 2016 at Chalmers University of Technology, Gothenburg, Sweden, where she currently works as a post-doc researcher. Her research interests include electric drive systems, mainly for vehicular applications, regarding component and system cooling, energy consumption, performance and cost.

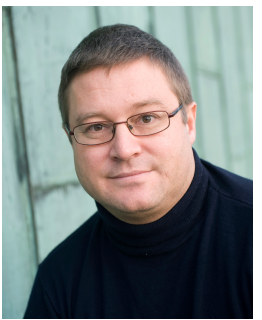

Torbjörn Thiringer works at Chalmers University of Technology, in Gothenburg, Sweden, as a professor in applied power electronics. He took his M.Sc. and Ph.D. at Chalmers University of technology in 1989 and 1996, respectively. His areas of interest include the modeling, control and grid integration of wind energy converters into power grids as well as power electronics and drives for other types of applications, such as electrified vehicles, buildings and industrial applications.



Rik W. De Doncker received the Ph.D. degree in electrical engineering from Katholieke Universiteit Leuven, Leuven, Belgium, in 1986. In 1987, he joined the University of Wisconsin, Madison, WI, USA, as a Visiting Associate Professor. After a short stay as an Adjunct Researcher at the Interuniversity Microelectronics Centre, Leuven, he joined, in 1989, the Corporate Research and Development Center, General Electric Company, Schenectady, NY, USA. In 1994, he joined Silicon Power Corporation, Malvern, PA, USA, a former division of General Electric Inc., as the Vice President of Technology. In 1996, he became a Professor with RWTH Aachen University, Aachen, Germany, where he currently leads the Institute for Power Electronics and Electrical Drives. Since 2006, he has been the Director of the E.ON Energy Research Center, RWTH Aachen University. Dr. De Doncker was the President of the IEEE Power Electronics Society (PELS) in 2005 and 2006. He was the founding Chairman of the German IEEE Industry Applications Society PELS Joint Chapter. In 2002, he received the IEEE Industry Applications Society Outstanding Achievement Award. In 2008, he received the IEEE Power and Energy Society Nari Hingorani Custom Power Award. In 2009, he led a Verband der Elektrotechnik, Elektronik, und Informationstechnik (VDE) / Energietechnische Gesellschaft (ETG) Task Force on Electric Vehicles. In 2010, he received an honorary doctor degree from TU Riga, Latvia. In 2013, he received the IEEE William E. Newell Power Electronics Award. 